\title{
Are You Back for Good or Still Shopping Around? Investigating Customers' Repeat Churn Behavior
}

\author{
V. Kumar* \\ Agata Leszkiewicz
}

Angeliki Herbst

November 9, 2017

Forthcoming in the Journal of Marketing Research

\begin{abstract}
Authors:
*V. Kumar (VK) is a Regents' Professor, Richard and Susan Lenny Distinguished Chair \& Professor of Marketing, the Executive Director of the Center for Excellence in Brand and Customer Management (CEBCM), and the Director of the Ph.D. Program in Marketing, J. Mack Robinson School of Business, Georgia State University, Atlanta, GA. VK has also been honored as the Chang Jiang Scholar, Huazhong University of Science and Technology, Wuhan, China; Fellow, Hagler Institute for Advanced Study, Texas A\&M University, College Station, TX; and Senior Fellow, Indian School of Business, Hyderabad, India. Email: vk@gsu.edu. Agata Leszkiewicz is a visiting scholar at the Center for Excellence in Brand and Customer Management (CEBCM), J. Mack Robinson School of Business, Georgia State University, Atlanta, GA. Email: aleszkiewicz@gsu.edu.

Angeliki Herbst (formerly Christodoulopoulou) is a doctoral student at the Center for Excellence in Brand and Customer Management (CEBCM), J. Mack Robinson School of Business, Georgia State University, Atlanta, GA. Email: achristodoulopoulou1@gsu.edu.

All authors contributed equally. We thank the Editor, the AE, and the review team for their constructive feedback during the revision process. We thank Mercedes Esteban-Bravo, Kihyun Hannah Kim, Alok Saboo, José M. Vidal-Sanz, Yi Zhao, and the select participants of the 2016 Winter AMA Conference and the 2015 Marketing Science Conference for their comments on the earlier versions of the paper. We thank Ericka Yates for her assistance and thank Renu for copyediting the earlier versions of the paper.
\end{abstract}




\title{
Are You Back for Good or Still Shopping Around? Investigating Customers' Repeat Churn Behavior
}

\begin{abstract}
Service firms develop win-back strategies to rectify issues that cause customer churn and rebuild the relationship with lost customers. To better support retention, it is important to understand how the revived relationship evolves and possibly ends again. To examine customers' repeat churn behavior, we develop a Mixture Cure Competing Risks model, jointly estimating the second lifetime duration, multiple churn reasons, and customers' heterogeneity in exhibiting a related churn reason. The proposed model is tested using a dataset from a large telecommunications provider including information on customer behavior and marketing activities during customers' first and second lifetimes. We find support for the existence of a cured group of returning customers, defined as those who are not susceptible to churn due to a repeated reason. Our findings suggest that mitigating repeat churn behavior can extend customers' second lifetime tenure and increase profitability by $\$ 150,000$ over the lifetime of the customers in the sample (leading to gains of over \$15 million for deferring second lifetime churn in a million returning customers), depending on the type of churn.
\end{abstract}

Keywords: second lifetime duration, repeat churn, defection reason, win-back offer, CRM, cure model, competing risks model, hazard model 
Recent developments in customer relationship management (CRM) examine the extended customer lifecycle, exploring what happens when customers suspend a service. In the wireless industry, carriers such as T-Mobile and Verizon offer a reimbursement of up to $\$ 650$ per line to cover early termination fees to customers who are willing to make a switch from another service provider (T-Mobile 2017; Verizon 2017). In the gas and energy industry, market deregulation has increased competition, giving the customer the power to choose the best provider with the help of dedicated websites such as Power2Switch.com. As a result of decreasing monetary switching costs, contractual service industries face a unique problem: customers tend to churn repeatedly. However, firms have begun to recognize that lost customers may not be "dead opportunities" (Griffin and Lowenstein 2001), and extend attractive promotional offers to win them back. After successful reacquisition, firms need to understand this renewed relationship to fortify customer retention strategies and contain the looming risk of churn.

Rebuilding the relationship with lost customers is the main objective of win-back management (Stauss and Friege 1999). The re-initiated customer-firm relationship, or a customer's second lifetime (SLT), is typically marked by the signing of a new contract. As such, we distinguish it from the customer's first lifetime (FLT) - the relationship with initially acquired prospects. The SLT is different from the FLT for both the customer and the firm. Reacquired customers' experience with the firm clearly distinguishes them from newly-acquired customers (Stauss and Friege 1999). They have knowledge and expectations about the firm's offerings and procedures gained in their FLT and through win-back interactions. From the firm's perspective, the revived customer relationship is distinct from the relationship with new customers because the firm has information about the reacquired customers' preferences from their past and present interactions (Griffin and Lowenstein 2001; Stauss and Friege 1999). Considering the FLT and 
SLT customer behavior and characteristics, the firm can offer them targeted and personalized services. Therefore, the clear distinction between the pre- and post-churn phases of the customerfirm relationship requires that SLT strategies are investigated in addition to FLT strategies.

The win-back literature has focused on several aspects of the SLT such as customer reacquisition, SLT duration and profitability (Kumar, Bhagwat, and Zhang 2015; Thomas, Blattberg, and Fox 2004). Prior research has identified the main reasons why customers quit services (Keaveney 1995), showing that knowledge of the problem areas can help the firm proactively address FLT churn (Stauss and Friege 1999; Tokman, Davis, and Lemon 2007). However, the repeat churn behavior of returning customers has not yet been investigated. Henceforth, we use the term repeat churn behavior, SLT churn behavior, or reason for SLT churn, to refer to the termination of customers' SLT and the reasons behind it. Although the reason for FLT churn is indicative of SLT duration (Kumar, Bhagwat, and Zhang 2015), questions remain if it is a significant predictor of the reason behind SLT churn. We believe additional research is needed to gain more insights into the SLT churn behavior.

Based on FLT reasons for churn, firms can identify areas for improvement and effectively engage in win-back dialogue with lost customers. If firms succeed in addressing the underlying cause for dissatisfaction, customers will not churn for the same reason in the future. We refer to such customers as cured customers. Cured customers are satisfied with the firm's win-back efforts to improve the problem areas underlying their FLT churn. However, this does not apply to every returning customer; there will be a share of uncured customers who are more likely to return to the firm only because of the incentives included in the firm's reacquisition activities. These customers may churn again for any reason, including the one that caused their FLT churn, despite the firm's reacquisition efforts. Therefore, we propose that the two types of 
returning customers, cured and uncured, are susceptible to different churn reasons in the future. Both types of customers are still at risk of defection in the SLT, whether for the same or other reasons, so predicting SLT churn remains a crucial aspect of managing reacquired customers.

Firms need to know when and why a returning customer will churn again, and how this propensity to repeat churn changes over time. For example, do price-sensitive customers churn earlier or later than quality-demanding customers? Further, given the firm's efforts to rectify problem areas underlying the first churn, is a returning customer still at risk of churning for the same reason again in the SLT, or is the damaged relationship with this customer cured, so that if they churn it will be for other reasons? If the latter is true, will a cured customer exhibit longer tenure compared to an uncured customer? Finally, CMOs want to know if a customer's SLT behavior is indicative of the propensity to repeat churn, understand how current marketing interventions influence SLT tenure, and how to design effective retention strategies.

This study attempts to provide answers to the above issues by developing a model of customers' repeat churn behavior using transactional data that document such behavior in a contractual industry. The rich dataset at our disposal includes FLT and SLT records of customer behavior - subscription details and referral activities, and the firm's marketing actions communications to customers, as well as FLT and SLT churn behavior. This is the first study using both FLT and SLT information on customer behavior and the firm's marketing activities. We model the SLT churn through a survival analysis approach, which is well-suited to include a) a churn probability that can change over time, b) right-censoring, and c) time-varying covariates. Since our focus lies on SLT retention, our analysis is conditional on customers being reacquired. To uncover the two groups of returning customers (cured and uncured), we draw upon the literature on mixture cure (MC) survival models. To allow for the SLT to terminate due to one of 
multiple competing events (i.e., causes for churn), we use the competing risks (CR) survival framework. The unifying framework is the mixture cure competing risks model (MCCR), which accounts for 1) the possible existence of a cured and an uncured customer group, where the former will not repeat the FLT churn reason (MC), and 2) multiple reasons to churn in both groups (CR). Basu and Tiwari (2010) first proposed an MCCR model describing different patterns of time dependence in the survival of cancer patients. We extend this framework by (a) allowing the customer to belong to one of two groups with a probability, (b) incorporating time dependence, and (c) including time-varying covariates for the prediction of SLT churn. This study contributes to the marketing literature in the following ways:

1. We predict the time and the reason for customers' SLT churn, and show that it is different from FLT churn.

2. We employ SLT information on customer service and behavior characteristics and marketing actions to predict customers' repeat churn behavior and thus help managers design retention strategies in real time.

3. We distinguish between two groups of returning customers, cured and uncured, where the former do not repeat the FLT churn reason.

4. We use FLT information on customer service and behavior characteristics and marketing actions to recognize cured customers and thus help managers leverage this knowledge in the renewed relationship.

5. We propose a unifying MCCR model which jointly accounts for the cured and uncured groups of customers and multiple reasons to repeat churn, while incorporating covariates to predict cure probabilities and SLT duration.

The rest of the article is organized as follows: First, we review the relevant customer SLT literature explaining the marketplace need, the research gap, and the contributions of this paper in each research area in more detail. Then, we discuss the empirical setting of our study, including the data set and the modeling framework. Subsequently, we introduce the relevant methodological literature and derive the MCCR model. Finally, we present the results and a discussion of our findings, their implications, limitations, and future research opportunities.

\section{SLT LITERATURE REVIEW}


Extant literature on customers' SLT has primarily focused on reacquisition, with select studies investigating SLT duration and profitability. Reacquisition is the first aspect of SLT management, aiming to identify and target lost customers who are worth reacquiring, and design win-back activities to bring them back and start their SLT. Stauss and Friege (1999) discuss the steps that firms should undertake to implement a win-back strategy based on customer value and reason for churn, in order to yield a higher return on reacquisition investment. Building on this framework, Griffin and Lowenstein (2001) provide advice on designing successful customer reacquisition strategies and practices. Reinartz, Krafft, and Hoyer (2004) show a positive association of the existence of systematic reacquisition processes with the strength of the organization.

Several factors influence a lapsed customer's decision to renew the contract. Win-back activities need to offer attractive incentives to convince the customer to renew the relationship, and may include an individually-adapted monetary compensation (a rebate, a coupon, a price discount, etc.), or service upgrade (Stauss and Friege 1999). Consistent with economic theory, larger monetary and non-monetary incentives increase the perceived value of the win-back offer and the reacquisition probability (Thomas, Blattberg, and Fox 2004; Tokman, Davis, and Lemon 2007). Adapting the win-back offer to address the reasons for customer defection has been recommended to improve reacquisition (Stauss and Friege 1999) and also empirically supported (Kumar, Bhagwat, and Zhang 2015; Tokman, Davis, and Lemon 2007). Furthermore, a customer's reacquisition probability is affected by their satisfaction from the interactions and outcomes of the revival process (Homburg, Hoyer, and Stock 2007); customer characteristics (Kumar, Bhagwat, and Zhang 2015; Thomas, Blattberg, and Fox 2004), including variety seeking and involvement (Homburg, Hoyer, and Stock 2007); as well as past experience, such as 
the FLT tenure, service experience, marketing communication, and the defection behavior (Kumar, Bhagwat, and Zhang 2015).

Research on aspects beyond customer reacquisition is scarce, despite the importance of SLT duration and profitability for customer retention. Strategies based on retention models developed for the FLT (e.g., Reinartz and Kumar 2003) are not directly applicable to the SLT, since the two lifetimes are conceptually different due to the knowledge and experience the reacquired customer has about the firm, and vice versa. Notable exceptions are the studies by Thomas, Blattberg, and Fox (2004), who examined the influence of the FLT duration, the defection duration (i.e., time elapsed since churn), and the offered price on SLT duration using a survival model assuming constant churn rates; and by Kumar, Bhagwat, and Zhang (2015), who investigated the impact of FLT experience and behavior on SLT duration using a Tobit type linear duration model.

Understanding why customers quit the service is a key element of CRM. Keaveney (1995) identified various reasons for customer defection. Among these reasons, some are beyond the firm's control, but the most frequent critical incidents are price and service issues (service failures, failed service encounters, and response to service failure). Customers' motives to churn are an important factor for segmentation and targeting of lapsed and reacquired customers (Stauss and Friege 1999), because customers who repeatedly switch between providers tend to have short SLTs. Bogomolova (2010) found that the customers who switch to the competition will have more positive brand evaluations and higher propensity to consider the brand in the future than customers who switch from the brand due to its negative qualities. In an empirical study, Kumar, Bhagwat, and Zhang (2015) show that a customer's motive for defection is a good predictor of their reacquisition likelihood, SLT duration, and SLT profitability. Specifically, 
customers churning for price reasons have higher probability of reacquisition than customers churning for service-related reasons, but their SLT is shorter, and their monthly profitability is lower.

Studying churn behavior of reacquired customers should be part of a holistic SLT management approach, as repeat churn has become a significant concern for firms in various industries but has been overlooked by the extant SLT literature. Table 1 shows how this study compares to relevant prior research studies modeling customer defection and/or reacquisition in contractual settings. The studies of Kumar, Bhagwat, and Zhang (2015) and Braun and Schweidel (2011) appear to be the closest benchmarks, but neither predicts repeat churn behavior, which is the first objective of our study. Specifically, Kumar, Bhagwat, and Zhang (2015) focus on the duration of the SLT, but overlook the reasons for SLT defection. Braun and Schweidel (2011) model both the time and reason for FLT churn, which we show is different from SLT churn. We also investigate whether customers' SLT churn patterns are different from their FLT churn reasons, which is not the case in any prior research. Further, we examine the effects of SLT customer behavior and marketing actions on SLT churn behavior, which is a significant development for SLT retention strategies over the research by Kumar, Bhagwat, and Zhang (2015), whose findings are based on historical FLT data. Accounting for time-varying SLT covariates is also a contribution over the Braun and Schweidel (2011) study, where only time-invariant geodemographic characteristics are included. Finally, we uncover the two groups of returning customers and examine the effects of win-back offers and FLT information on the likelihood of customers' being in the cured group. To the best of our knowledge, this is the first attempt to comprehensively and empirically study SLT churn behavior, in terms of both the SLT duration and the reasons behind relationship termination. 


\section{EMPIRICAL SETTING}

The data used in this study comes from a U.S.-based telecommunications provider, comprising of individual-level data on a random sample of 10,000 customers, reacquired in January 2012, and tracked throughout their SLT until December 2015. We randomly assigned 7,054 customers to the calibration sample, and the remainder 2,946 customers constitutes our holdout sample used for model validation. The available information includes data collected from each customer during the observation period: the time and reason of churn, customer activities, and marketing actions by the firm. We also have historical information on each customer: customer activities and marketing actions in the FLT, the time and reason to churn, a record of the lapse duration, and the type of win-back offer they received. Figure 1 illustrates the timeline of the customer-firm relationship for customers in our sample.

Customers' FLT began with the initial acquisition and ended upon the original contract termination $^{1}$. The firm obtained information about the reason for their defection through a representative-administered survey, and classified them as related to price and/or service ${ }^{2}$. In December 2011, the firm conducted a one-time reacquisition campaign and mailed out attractive win-back offers to all customers who had ended their FLT in the previous two to six months. Only first-time churners were contacted. To address the most common reasons for customer churn, the firm designed the win-back offers based on a price discount, a service upgrade, or a

\footnotetext{
${ }^{1}$ In this industry, customers may change conditions to their contracts before expiration by, for example, purchasing additional services and bundling them or changing the rate plan, which may involve signing new contracts for addon services. We attribute a customer's FLT and/or SLT as the customer-firm business relationship, which stops when the customer suspends all services.

2 There is a small fraction of customers (less than 2\%) who defected due to reasons that do not fall under the any of the above-mentioned categories (classified by the firm as other reasons). This category represents factors that are outside of the firm's control and, therefore, the firm did not target such customers with win-back offers.
} 
combination of a price discount and a service upgrade. All offers were similar in value: the price discount included in the bundled offer was lower than the one in the standalone price win-back, and so was the service upgrade benefit. These offers were randomly assigned to the lapsed customers and expired after 30 days. The promotional benefits were in effect only for the first six months of the customer's renewed contract, which was typically signed for a period of twentyfour months, but could be suspended without penalty after the promotional period expired. After twenty-four months, the contract was automatically renewed until the customer suspended the service, or chose a new contract. As such, the SLT began with re-signing a customer after the initial churn period, and either ended with cancellation of all their services (for the second time) or lasted beyond the observation window. Each churning customer was asked to participate again in a standard exit interview administered over the phone.

--- Insert Figure 1 about here ---

During the FLT and SLT the firm kept records of each customer's behavior and marketing contacts. The FLT data contains historical information measured in yearly averages over the FLT or at the end of the FLT (it is aggregate and time-invariant). Customers' service characteristics include the average monthly FLT revenue from their service purchases and the number of services included in the contract throughout the FLT. More aspects of customer experience are captured through their successful referrals of new customers to the firm and their complaints. Firm actions include service recovery records ${ }^{3}$ as well as customer retention efforts in the form of marketing communications through phone calls, emails, and direct mail (measured

\footnotetext{
${ }^{3}$ In this setting, complaints and recoveries are only partially related. Examples of service recoveries include restoring service after outage, or offering free service (or discounts) for a short period of time. The firm can restore service even without a customer notification (e.g., if an entire area is affected). On the other hand, not all complaints are considered by the firm. Thus, there is not always a direct link between a customer filing a complaint and the firm considering it or not. The correlation between complaints and recoveries in our sample is 0.13 in the SLT and 0.11 in the FLT (both are significant).
} 
in yearly averages). Each customer's defection period is the time elapsed (in days) between the termination of their first contract and the start of a new one. The data collected during the observation window includes the same information on customer behavior, but it pertains to the SLT and is observed monthly, including: the revenue from customer's SLT service purchases, the level of their cross-buy across different services, their successful referrals of new customers to the firm, and their complaints. Firm actions like service recovery efforts, are also recorded on a monthly basis. Marketing communications are captured by the monthly number of phone calls made, emails sent, and direct mails sent to each customer. We also have information on the duration of the promotion embedded in the win-back offer, captured by an indicator variable taking a value of 1 for the months when the offer is in effect (i.e., the customer pays a discounted price and/or receives a free service upgrade), and 0 otherwise. We note demographic information about the customer's gender, age, income, household size, and education as the measures of observed heterogeneity at our disposal. Table 2 summarizes the available data and details the variable operationalization. The descriptive statistics are presented in Table 3.

--- Insert Tables $2 \& 3$ about here ---

Since our main objective is to investigate repeat churn behavior, we first examine the relationship between customers' FLT and SLT defection reasons, presented in Table 4. There are two distinct churn motives ("price" and "service"), but three churn categories ("price", "service", and "price-and-service"). We see that 2,320 $(2,106)$ customers ended their FLT (SLT) because of price, 2,430 (2,124) ended because of service issues, and 2,304 (2,082) suspended the contract reporting both issues as the reason for defecting, which we distinguish here as a separate churn category. Around ten percent of the reacquired customers maintained service until the end of the observation period, thus censoring does not pose a threat. Although the marginal distributions of 
FLT and SLT churn appear evenly distributed among defection categories, their joint distribution reveals that customers generally do not report the exact same churn category twice. This is true in only about 32 percent of the cases. Therefore, information on past churn reasons is not sufficient to predict future churn behavior, consistent with research suggesting that the FLT can be different from the SLT (Stauss and Friege 1999).

--- Insert Table 4 about here ---

\section{Modeling Framework}

The customer-firm relationship is conceptually analogous to a patient-doctor relationship. Based on the patient's history and symptoms, the doctor gives a diagnosis and determines the course of treatment. If the treatment is successful, the patient will recover from the illness, but will eventually die for other reasons. If the treatment is unsuccessful, the patient may succumb to the illness or die of any other disease (whichever comes first). Similarly, customers' FLT churn reasons are symptomatic of the dissatisfaction areas, so the firm will try to amend them. If this "treatment" is successful, the customer will become cured and not succumb to this type of churn. Otherwise, the customer will stay dissatisfied with that aspect of the service. Regardless of the cure status, the customer is still vulnerable to churn in the SLT because of other reasons. Thus, as the doctor keeps his patients under observation following treatment, the firm should monitor the customers' behavior for signs of possible SLT defection. With this in mind, we build a model of repeat churn behavior whose overview is presented in Figure 2 .

--- Insert Figure 2 about here ---

Repeat churn behavior. To explain repeat churn behavior, we jointly predict the SLT tenure and defection motive (dependent variable), leveraging the individual-level information on SLT customer characteristics and firm activities (covariates). We expect customer behavior associated with positive (vs. negative) experience to be indicative of longer (vs. shorter) SLT 
tenures, and assume a homogenous effect of covariates on the type of churn (Kumar, Bhagwat, and Zhang 2015). Specifically, SLT revenue should be positively related to SLT duration, consistent with literature on customer retention (Reinartz and Kumar 2003). Therefore, high revenue customers will have lower churn propensity. Cross-buying behavior and relationship duration are positively associated in the FLT (Reinartz and Kumar 2003), but an inverse U-shape association has been documented between FLT cross-buy and SLT duration (Kumar, Bhagwat, and Zhang 2015). Accordingly, we expect customers with moderate levels of cross-buy to be the least likely to churn, as implied by the inverse U-shape relation between contemporary (SLT) cross-buy and SLT duration. Customer referrals indicate satisfaction with the firm (Biyalogorsky, Gerstner, and Libai 2001), which in turn is leads to longer relationship duration (Bolton 1998). Therefore, we expect referrals to be associated with longer SLT tenures and lower SLT churn propensity. Complaints express customer dissatisfaction with the service or the firm, so they should be negatively related to SLT duration, while recovery efforts should have a positive effect. We generally expect more complaints (vs. service recoveries) to indicate a higher (vs. lower) propensity of suspending service.

Marketing communications should have positive and synergistic effects on SLT duration, consistent with the evidence obtained from different contact modes (Kumar, Bhagwat, and Zhang 2015; Reinartz, Thomas, and Kumar 2005). Thus, we expect marketing communications to be negatively associated with a customer's SLT churn. Furthermore, observed heterogeneity is captured through the available demographic characteristics. Our expectations for their association with customers' SLT churn are guided by findings of Kumar, Bhagwat, and Zhang (2015) in a similar setting. Most of the demographic variables are expected to indicate longer SLT tenures, and accordingly, have a negative association with churn timing. 
Finally, we control for certain FLT, defection, and win-back aspects. Specifically, we control for the months when the win-back promotion is in effect. During this period, customers enjoyed attractive win-back benefits and faced a penalty for contract cancelation - a strong incentive to maintain contract. Therefore, this promotion should be negatively related to SLT churn timing. Regarding the defection period, prior research (Kumar, Bhagwat, and Zhang 2015) has found it has a nonlinear effect on the likelihood of reacquisition, but not on the SLT duration. We cautiously expect the length of the defection period to be negatively related to the SLT churn propensity, but also test for the existence of a diminishing effect. Finally, we control for the length of the customer's FLT and the average monthly revenue generated by the customer during the FLT. These controls indicate satisfaction with the firm, leading to a positive association with relationship duration (Bolton 1998), so we expect a negative relationship with SLT churn.

Cured vs. uncured customers. We distinguish between two types of returning customers, characterized by unique patterns of first and second churn behavior. They emerge as a result of the firm's efforts to improve on dissatisfaction areas causing customers to end their FLTs. These efforts are implemented through various tools during the post-churn dialogue (win-back offers in this context). If the firm rectifies the issues underlying their FLT churn, some returning customers will be cured. Since there are two distinct churn reasons, the returning customers can be "price-cured" and/or "service-cured". Consequently, customers who ended their FLT because of price (service), if cured, will defect due to the remaining non-price (non-service) reason in the SLT, i.e., service (price). Customers who ended their FLT due to both reasons (price and service), if cured, will become price-cured and service-cured, and will not succumb to any type of SLT churn. In contrast, uncured customers will be susceptible to all churn categories in their 
SLTs, regardless of the FLT churn reason. The shaded box in Figure 2 illustrates this idea in this empirical setting.

Customers' latent cure status (binary dependent variable) can be predicted by incorporating the information available to managers at the time of reacquisition. Specifically, the cure probability predictors include the FLT customer service and behavior characteristics in terms of tenure, monthly revenue, cross-buying, referral activity, and complaining. We also include the effects of FLT firm actions regarding service recoveries and marketing communications through phone calls, emails, and direct mailings. Our general expectations are parallel to the discussion on SLT duration. The more positive the FLT relationship is, the easier it is for the firm to successfully address the dissatisfaction area, increasing the probability that a customer will be cured. The effects of observed heterogeneity on the cure probability are captured through the demographic variables. Lastly, win-back offers with incentives that correspond to the FLT reason have greater potential to improve the relationship with the customer than ones without such incentives, increasing the cure chances.

\section{MIXTURE CURE COMPETING RISKS MODEL}

We develop a joint model of the time and reason for SLT churn in which cured and uncured customers are susceptible to different types of churn. The proposed model is based on a survival analysis framework, previously adopted in various CRM applications (Braun and Schweidel 2011; Kumar, Zhang, and Luo 2014). Seetharaman and Chintagunta (2003) give an excellent review different survival models with an application to purchase timing decisions. To predict when SLT churn will happen and what type of event it will be, we apply the competing risks (CR) method (Kalbfleisch and Prentice 2002). This methodology has been used in marketing to model purchase timing and brand choices (Seetharaman and Chintagunta 2003) and 
customers' FLT churn behavior (Braun and Schweidel 2011). There are a couple of limitations of the CR approach relevant to this study. First, it assumes that the competing risks are mutually exclusive, while here one of the churn reasons is a combination of the others ("price-andservice" reason $)^{4}$. In our model setup, it is treated as a separate competing risk, and we interpret the results accordingly. Second, the CR method assumes that all individuals are exposed to the same risks.

The development of mixture-cure (MC) models is mainly attributed to the progress in cancer research (Berkson and Gage 1952; Farewell 1982). As a result of the treatment (or the cure), a fraction of long-term survivors emerges in the population of patients, $0<\mathrm{p}<1$, affecting the subsequent duration through the survival function $S(t)=p+(1-p) S_{0}(t)$, which does not tend to 0 but has a probability $\operatorname{limit} \lim _{\mathrm{t} \rightarrow \infty} \mathrm{S}(\mathrm{t})=\mathrm{p}$. This is a property unique to the cure model, implying that only some individuals will ever experience an event. The cure model is a mixture model, as the survival function captures the unobserved heterogeneity of failure times in the cured and uncured subpopulations, with $S_{1}=1$ being the survival function of the cured group. The model has various applications in marketing: Sinha and Chandrashekaran (1992) modeled banks' adoption of ATMs, allowing some banks to be non-adopters; Srinivasan, Lilien, and Rangaswamy (2006) studied the emergence of a dominant design in a new product category. However, MC models do not allow for multiple types of events, which prevents us from understanding the time dependence in several reasons for SLT churn. Furthermore, MC applications are limited by the assumption that an individual is cured of one risk only.

\footnotetext{
${ }^{4}$ When event types are not mutually exclusive, similar competing risks are usually aggregated into a single risk category. However, this it is not advisable here, as the "price-and-service" reason cannot be clearly classified into "price" or "service" category.
} 
A few studies have brought the MC and CR approaches under a unified framework. Larson and Dinse (1985) developed a mixture competing risks model where the probability for the type of failure was modeled as a logistic regression, and the conditional time-to-event followed a piecewise exponential model. Basu and Tiwari (2010) developed a Bayesian model for cancer survival with competing causes of death, where the patient population is a mixture of cured and uncured individuals, and the primary risk is removed for the cured patients. Therefore, it allows for different risk sets in the cured and uncured group.

We incorporate the unified MC and CR frameworks to a unique marketing application, where the reasons for SLT churn are the competing risks and win-back offers act as cures. Our approach offers several modeling contributions. First, we propose a novel way to address a problem of overlapping competing risks. Second, we allow for the cures to target more than one risk. Furthermore, our MCCR model is discrete-time and incorporates monthly SLT information in the hazard rates. We also use FLT information to parametrize the cure probability. We develop the model in several steps. First, we introduce the competing risks to account for multiple causes for churn. The cure effect is next incorporated as the MCCR model. To maintain notational compactness, the time-varying covariates for the SLT duration and the predictors of cure probability are included later, followed by a discussion of endogeneity concerns.

\section{Model Setup}

Assume a sample of $\mathrm{N}$ reacquired customers, and let $\mathcal{S}=\{1, \cdots, s\}$ be a set of $s$ mutually exclusive churn reasons, so $\mathcal{S}=\{$ price, service $\}$ in this setting. At the end of the FLT (SLT) the individual may report any combination of reasons in $\mathcal{S}$ that caused them to suspend the contract. Thus, there are $\mathrm{k}=2^{\mathrm{s}}-1$ ways the customer's FLT (SLT) can end, forming the risk set $\mathcal{P}^{+}(\mathcal{S})=$ $\{\mathcal{C}: \mathcal{C} \subseteq \mathcal{S}$ and $\mathcal{C} \neq \varnothing\}$. This is the power set of $\mathcal{S}$, excluding the empty set, and in this setting $\mathcal{P}^{+}(\mathcal{S})=\{\{$ price $\},\{$ service $\}$, price, service $\}$. For the $i$ th individual the observed data is 


$$
\left(t_{i}, C_{i t}, x_{i t}, x_{i}{ }^{F L T}, C_{i}{ }^{F L T}\right) \text { with } t=1, \ldots, t_{i}
$$

where $t_{i}$ is the observed SLT duration in days. This can be divided into intervals with grouping points $\left[t_{0}, t_{1}\right),\left[t_{1}, t_{2}\right), \cdots,\left[t_{a-1}, t_{a}\right),\left[t_{a i}, t_{\infty}\right)$, where $t_{0}=0, t_{a i}=t_{i}$ is the observed SLT duration. The intervals are not required to be of the same length. $C_{\mathrm{it}}$ is a vector taking values $\mathrm{C}_{\mathrm{it}}=\mathrm{j}\left(\mathcal{C}_{\mathrm{j}} \in \mathcal{P}+(\mathcal{S})\right.$, $\mathrm{j}=1, \ldots, \mathrm{k})$ if churn is observed in period $t$ and 0 otherwise. We also use $\mathrm{C}_{\mathrm{i}}=\Sigma_{\mathrm{t}} \mathrm{C}_{\mathrm{it}}$ to denote censored $\left(\mathrm{C}_{\mathrm{i}}=0\right)$ and uncensored cases $\left(\mathrm{C}_{\mathrm{i}}>0\right)$. The vector of covariates $\mathrm{x}_{i t}$ are the variables predicting the SLT duration observed in month $t$, and $\mathrm{xi}_{\mathrm{i}}^{\mathrm{FLT}}$ comprises of variables affecting the cure probability. Finally, $\mathrm{C}_{\mathrm{i}} \mathrm{FLT}=\mathrm{l}\left(\mathcal{C}_{\mathrm{l}} \in \mathcal{P}^{+}(\mathcal{S}), \mathrm{l}=1, \ldots, \mathrm{k}\right)$ represents all reason(s) why the customer churned in the FLT ${ }^{5}$. Without loss of generality, we assume that the churn probability and the covariates are constant within the time interval. The observed outcome is the pair $\left(\mathrm{t}_{\mathrm{i}}, \mathrm{C}_{\mathrm{it}}\right)$.

\section{Modeling Multiple Causes to Churn with the Competing Risks Framework}

An active customer is at risk of churning due to any of the competing risks in $\mathcal{P}^{+}(\mathcal{S})$, and the time to churn is a random process specific to each risk. Once a customer churns due to one type of churn, others are no longer possible, so we only observe the duration $t=\min t_{j}, j=1, \ldots, k$. Conditional on having a contract just before $t$, the probability that the customer churns in time $t$ due to risk $j$ is the cause-specific hazard is $h_{j}\left(t \mid \alpha_{j}, \gamma_{j}\right)=\alpha_{j} \gamma_{j} \gamma_{j}-1$, and is assumed to follow a Weibull distribution with $\alpha$-scale parameter and $\gamma$-shape parameter $(\alpha, \gamma>0)$. The Weibull specification allows for both proportional and accelerated effect of the covariates on the survival, and was adopted previously in related literature (e.g., Braun and Schweidel 2011; Kumar, Zhang, and Luo 2014). The effect of all forces causing the customer to churn is captured through the sum of the integrated cause-specific hazards $H\left(t \mid \theta_{1}, \ldots, \theta_{k}\right)=\sum_{j=1}^{k} \alpha_{j} t^{\gamma_{j}}, \theta_{j}=\left[\alpha_{j}, \gamma_{j}\right]$. Another

\footnotetext{
${ }^{5}$ We require that the churn causes are coded in the same way for the FLT and SLT. For example, in this application $\mathcal{C}_{1}=\{$ price $\}, \mathcal{C}_{2}=\{$ service $\}$, and $\mathcal{C}_{3}=\left\{\{\right.$ price $\},\{$ service $\}$ are coded as $\mathrm{C}_{\mathrm{it}}=1,2,3$, respectively.
} 
relevant quantity is the survival function, defined as a probability that the customer maintains the service until period $t$, which in the CR context implies that none of the k events occur before $t$. Under risk independence the survival function is $\mathrm{S}(\mathrm{t})=\prod_{j} \mathrm{~S}_{\mathrm{j}}\left(\mathrm{t}_{\mathrm{j}}\right)=\exp (-\mathrm{H}(\mathrm{t}))$, and it is the likelihood contribution of a customer $i$ who does not churn within the observation window. If customer churn is observed, $\mathrm{C}_{\mathrm{i}}=\mathrm{j}$, then their likelihood contribution is the hazard rate corresponding to risk $j$ times the survival function. Combining right-censored and complete durations $^{6}$, the likelihood function is:

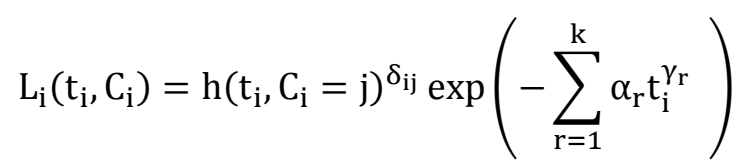

where $\delta_{\mathrm{ij}}=\mathrm{I}\left[\mathrm{C}_{\mathrm{i}}=\mathrm{j}\right]$.

\section{Defining the Mixture of Cured and Uncured Customers}

Consider a customer who ended their FLT due to one of the churn reasons in $\mathcal{S}$, or any possible combination thereof, indicated by $\mathrm{C}_{\mathrm{i}} \mathrm{FLT}=\mathrm{l}\left(\mathcal{C}_{\mathrm{l}} \in \mathcal{P}+(\mathcal{S})\right)$. If cured, this individual will not repeat any churn reason(s), and SLT and FLT churn reasons will not have common elements, i.e. $\mathcal{C}_{\mathrm{j}} \cap \mathcal{C}_{\mathrm{l}}=\varnothing$. Subscripts $(\mathrm{j}, 1)$ represent the reason for the second and first churn. Formally, a cured customer is susceptible to risks from a reduced set $\mathcal{P}^{-1}(\mathcal{S})=\left\{\mathcal{A}: \mathcal{A} \subseteq \mathcal{S}\right.$ and $\left.\mathcal{A} \cap \mathcal{C}_{1}=\emptyset\right\}$, and in this application $\mathcal{P}^{-1}(\mathcal{S})=\{$ service $\}, \mathcal{P}^{-2}(\mathcal{S})=\{$ price $\}, \mathcal{P}^{-3}(\mathcal{S})=\emptyset$. It follows that if $\mathcal{C}_{\mathrm{j}} \cap \mathcal{C}_{\mathrm{l}} \neq \emptyset$ we know that the customer is uncured (Case 1). When the customer churns because of risk in $\mathcal{P}^{-1}(\mathcal{S})$ (Case 2), or maintains contract beyond the observation window (Case 3), the cure status is unobserved. We identify these customers with an asterisk in Table 4 (around $31 \%$ of the sample). We also define a (partially) unobservable vector $Q_{i}$ taking values 1 if the customer is cured and 0 otherwise, and the probability $\mathrm{p}_{\mathrm{l}}=\operatorname{Pr}\left(\mathrm{Q}_{\mathrm{i}}=1 \mid \mathrm{C}_{\mathrm{i}} \mathrm{FLT}=\mathrm{l}\right)$. The upper bound for $\mathrm{p}_{\mathrm{l}}$ is obtained after

\footnotetext{
${ }^{6}$ The model can be extended to include left censoring, but this is not a concern in the present data setting.
} 
excluding Case 1 , and equals sup $\mathrm{p}_{\mathrm{l}}=1-\sum_{\mathrm{i}} \Sigma_{\mathrm{j}} \mathrm{I}\left[\mathrm{C}_{\mathrm{i}}=\mathrm{j}\right] / \Sigma_{\mathrm{i}} \mathrm{I}\left[\mathrm{C}_{\mathrm{i}}^{\mathrm{FLT}}=\mathrm{l}\right]\left(\forall \mathrm{j}: \mathcal{C}_{\mathrm{j}} \cap \mathcal{C}_{\mathrm{l}} \neq \emptyset\right)$. The overall integrated hazard affects the survival of the cured and uncured group, respectively $\mathrm{S}_{\mathrm{l}}\left(\mathrm{t} \mid \mathrm{Q}_{\mathrm{i}}=1\right)=\exp \left(-\Sigma_{\mathrm{j} \in \mathcal{P}^{-1}} \mathrm{H}_{\mathrm{j}}\right)$ and $\mathrm{S}_{\mathrm{l}}\left(\mathrm{t} \mid \mathrm{Q}_{\mathrm{i}}=0\right)=\exp \left(-\Sigma_{\mathrm{j} \in \mathcal{P}^{+}} \mathrm{H}_{\mathrm{j}}\right)$. With latent cure status, the survival function is a mixture, $\mathrm{S}_{l}(\mathrm{t})=\mathrm{p}_{1} \mathrm{~S}_{l}\left(\mathrm{t} \mid \mathrm{Q}_{\mathrm{i}}=1\right)+\left(1-\mathrm{p}_{l}\right) \mathrm{S}_{l}\left(\mathrm{t} \mid \mathrm{Q}_{\mathrm{i}}=0\right)$, since the customer may belong to either group. Three cases contribute to the likelihood in the following way:

Case 1. The customer's SLT churn occurs in time $t_{i}$ and has common elements with the FLT churn $\left(Q_{i}=0, \mathcal{C}_{j} \cap \mathcal{C}_{1} \neq \emptyset\right)$ :

We observe the cure status. Therefore, the customer belongs to the uncured group with survival probability $\operatorname{Pr}\left(\mathrm{Q}_{\mathrm{i}}=0\right) \mathrm{Sl}_{\mathrm{I}}\left(\mathrm{t} \mid \mathrm{Q}_{\mathrm{i}}=0\right)$. The contribution to the likelihood is

$$
\operatorname{Pr}\left(\mathrm{t}_{\mathrm{i}}, \mathrm{C}_{\mathrm{i}}=\mathrm{j}\right)=\left(1-\mathrm{p}_{\mathrm{l}}\right) \alpha_{\mathrm{jl}} \gamma_{\mathrm{jl}} \mathrm{t}_{\mathrm{i}}^{\gamma_{\mathrm{j} 1}-1} \exp \left(-\sum_{\mathrm{r}=1}^{\mathrm{k}} \alpha_{\mathrm{rl}} \mathrm{t}_{\mathrm{rl}}\right)
$$

Case 2. The customer's SLT churn occurs in time $t_{i}$ and has no common elements with the FLT churn $\left(\mathcal{C}_{\mathrm{j}} \cap \mathcal{C}_{1}=\varnothing\right)$ :

The cure status is not observable, so the customer has a mixture survival function. The contribution to the likelihood is

$$
\operatorname{Pr}\left(\mathrm{t}_{\mathrm{i}}, \mathrm{C}_{\mathrm{i}}=\mathrm{j}\right)=\alpha_{\mathrm{jl}} \gamma_{\mathrm{jl}} \mathrm{t}_{\mathrm{i}}^{\gamma_{\mathrm{jl}}-1}\left[\mathrm{p}_{\mathrm{l}} \exp \left(-\sum_{\mathrm{r} \in \mathcal{P}^{-1}(\mathcal{S})} \alpha_{\mathrm{rl}} \mathrm{t}^{\gamma_{\mathrm{rl}}}\right)+\left(1-\mathrm{p}_{\mathrm{l}}\right) \exp \left(-\sum_{\mathrm{r}=1}^{\mathrm{k}} \alpha_{\mathrm{rl}} \mathrm{t}_{\mathrm{rl}}\right)\right] \text {. }
$$

Case 3. The customer does not churn in the observation period $\left(\mathrm{C}_{\mathrm{i}}=0\right)$ :

The cure status is not observable. The likelihood contribution of a censored observation is the mixture survival function (expression in outer brackets of Case 2).

To compute the hazard rates for Cases 1 and 2, we have used the relation $H=-\log (S)$ and $\mathrm{h}=\partial \mathrm{H} / \partial \mathrm{t}$. We provide more derivation details in the Web Appendix. For customer $i$, who churned due to competing risk $l$ in the FLT, the likelihood contribution is constructed by combining the three different ways in which the SLT can end (Cases 1-3):

$$
\begin{aligned}
\mathrm{L}_{\mathrm{il}}\left(\mathrm{t}_{\mathrm{i}}, \mathrm{C}_{\mathrm{i}} \mid \mathrm{C}_{\mathrm{i}}^{\mathrm{FLT}}=\right. & \mathrm{l})=\mathrm{h}\left(\mathrm{t}_{\mathrm{i}}, \mathrm{C}_{\mathrm{i}}=\mathrm{j}\right)^{\delta_{\mathrm{ij}}} \\
& \times\left[\left(1-\delta_{\mathrm{il}}\right) \mathrm{p}_{\mathrm{l}} \exp \left(-\sum_{\mathrm{r} \in \mathcal{P}^{-1}(\mathcal{S})} \alpha_{\mathrm{rl}} \mathrm{t}_{\mathrm{i}} \gamma_{\mathrm{rl}}\right)+\left(1-\mathrm{p}_{\mathrm{l}}\right) \exp \left(-\sum_{\mathrm{r}=1}^{\mathrm{k}} \alpha_{\mathrm{rl}} \mathrm{t}_{\mathrm{i}} \gamma_{\mathrm{rl}}\right)\right]
\end{aligned}
$$

where $\mathrm{j} \neq \mathrm{I}, \delta_{\mathrm{i} i}=I\left[\mathcal{C}_{\mathrm{j}} \cap \mathcal{C}_{\mid \neq \emptyset} \neq\right.$, and $\delta_{\mathrm{ij}}=I\left[\mathcal{C}_{\mathrm{i}}=\mathrm{j}\right]$. 


\section{Capturing the Effects of Marketing and Customer Behavior}

Since the SLT covariates are observed monthly, the survival probability can be reformulated as a product of survival functions evaluated over all months the customer maintained service $\left(\mathrm{C}_{\mathrm{it}}=0\right)$. For the month $\mathrm{t}$ when churn is observed, and $\mathrm{C}_{\mathrm{it}}=\mathrm{j}$, the hazard is evaluated on period $\left[\mathrm{t}_{\mathrm{a}-1}, \mathrm{t}_{\mathrm{a}}\right.$ ), for details see Seetharaman and Chintagunta (2003). Therefore, the likelihood of the competing risks model (M1) rearranged in the discrete time setting to include time-varying covariates is:

$$
\mathrm{L}_{\mathrm{i}}\left(\mathrm{t}_{\mathrm{i}}, \mathrm{C}_{\mathrm{it}}\right)=\left(1-\exp \left(-\mathrm{l}\left(\mathrm{x}_{\mathrm{it}_{\mathrm{t}_{\mathrm{i}}}}\right) \int_{\mathrm{t}_{\mathrm{a}_{\mathrm{i}}}-1}^{\mathrm{t}_{\mathrm{a}_{\mathrm{i}}}} \mathrm{h}_{\mathrm{j}}(\mathrm{u}) \mathrm{du}\right)\right)^{\delta_{\mathrm{ijt}}} \prod_{\mathrm{v}=1}^{\mathrm{a}_{\mathrm{i}}-\delta_{\mathrm{i}}} \exp \left(-\mathrm{l}\left(\mathrm{x}_{\mathrm{iv}}\right) \sum_{\mathrm{r}=1}^{\mathrm{c}} \int_{\mathrm{t}_{\mathrm{v}-1}}^{\mathrm{t}_{\mathrm{v}}} \mathrm{h}_{\mathrm{j}}(\mathrm{u}) \mathrm{du}\right)(\mathrm{M} 1 \mathrm{X})
$$

where $\delta_{\mathrm{ijt}}=\mathrm{I}\left[\mathrm{C}_{\mathrm{it}}=\mathrm{j}\right], \delta_{\mathrm{i}}=\Sigma_{\mathrm{j}} \Sigma_{\mathrm{t}} \delta_{\mathrm{ijt}}$. Under Weibull specification, the integrals in (M1X) have a closed form. Finally, the discrete-time mixture-cure competing risks model with covariates has a likelihood of the form:

$$
\begin{aligned}
& \mathrm{L}_{\mathrm{i}}\left(\mathrm{t}_{\mathrm{i}}, \mathrm{C}_{\mathrm{it}}\right)=\left(1-\exp \left(-\mathrm{l}\left(\mathrm{x}_{\mathrm{it}_{\mathrm{i}}}\right) \int_{\mathrm{t}_{\mathrm{a}_{\mathrm{i}}}-1}^{\mathrm{t}_{\mathrm{i}}} \mathrm{h}_{\mathrm{j}}(\mathrm{u}) \mathrm{du}\right)\right)^{\delta_{\mathrm{ijt}}} \\
& \times \prod_{v=1}^{a_{i}-\delta_{i}}\left[\left(1-\delta_{i l}\right) p_{1} \exp \left(-l\left(x_{i v}\right) \sum_{r \neq l} \int_{v-1}^{v} h_{r}(u) d u\right)+\left(1-p_{1}\right) \exp \left(-l\left(x_{i v}\right) \sum_{r=1}^{c} \int_{v-1}^{v} h_{r}(u) d u\right)\right]
\end{aligned}
$$

where the indicators have been defined previously. Here the Weibull scale parameter $\alpha_{\mathrm{jl}}$ becomes a cause-specific intercept $\exp \left[\log \alpha_{\mathrm{j}}, \mathrm{l}\left(\mathrm{x}_{\mathrm{it}}\right)\right]$, and $\mathrm{l}\left(\mathrm{x}_{\mathrm{it}}\right)$ is a linear predictor

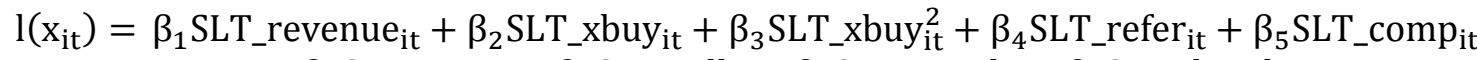

$$
\begin{aligned}
& +\beta_{6} \text { SLT_reco }_{i t}+\beta_{7} \text { SLT_call }_{\text {it }}+\beta_{8} \text { SLT_email }_{i t}+\beta_{9} \text { SLT_dmail }_{\text {it }} \\
& +\beta_{10} \text { SLT_call }_{\text {it }} * \text { SLT_email }_{i t}+\beta_{11} \text { SLT_Call }_{\text {it }} * \text { SLT_dmail }_{\text {it }} \\
& +\beta_{12} \text { SLT_email }_{i t} * \text { SLT_dmail }{ }_{i t}+\beta_{13} \text { SLT_win_promo }_{\text {it }}+\beta_{14} \text { taway } \\
& +\beta_{15} \text { taway }{ }^{2}+\beta_{16} \text { FLT_tenure }+\beta_{17} \text { FLT_revenue }+\beta_{18} \text { gender }+\beta_{19} \text { age } \\
& +\beta_{20} \text { income }+\beta_{21} \text { hhold }+\beta_{22} \text { educ }
\end{aligned}
$$

which measures the effects of customer service and behavior characteristics and marketing actions on repeat churn behavior, leveraging the panel data structure. 


\section{Identifying Cured and Uncured Groups}

The cure probability $p_{l}$ can be parameterized using the information available to the firm at the time of reacquisition to identify the characteristics of customers with high cure probability. Similar to other marketing applications of MC models (Sinha and Chandrashekaran 1992;

Srinivasan, Lilien, and Rangaswamy 2006) we use a logit link

$$
\begin{aligned}
& \log \frac{\mathrm{p}_{\mathrm{l}}}{1-\mathrm{p}_{\mathrm{l}}}=\lambda_{1, \mathrm{l}} \mathrm{FLT}_{-} \text {tenure }+\lambda_{2, \mathrm{l}} \text { FLT_revenue }+\lambda_{3, \mathrm{l}} \mathrm{FLT}_{-} \text {xbuy }+\lambda_{4, \mathrm{I}} \mathrm{FLT}_{-} \mathrm{xbuy}^{2} \\
& +\lambda_{5,1} \text { FLT_refer }+\lambda_{6,1} \text { FLT_comp }+\lambda_{7,1} \text { FLT_reco }+\lambda_{8,1} \text { FLT_call } \\
& +\lambda_{9,1} \text { FLT_email }+\lambda_{10,1} \text { FLT_dmail }+\lambda_{11,1} \text { FLT_call } * \text { FLT_email } \\
& +\lambda_{12,1} \text { FLT_call } * \text { FLT_dmail }+\lambda_{13,1} \text { FLT_email } * \text { FLT_dmail }+\lambda_{14,1} \text { gender } \\
& +\lambda_{15, \mathrm{l}} \text { age }+\lambda_{16, \mathrm{l}} \text { income }+\lambda_{17, \mathrm{l}} \text { hhold }+\lambda_{18, \mathrm{l}} \text { educ }+\lambda_{19, \mathrm{l}} \text { win_pri } \\
& +\lambda_{20,1} \text { win_ser }
\end{aligned}
$$

Identification concerns arise in this setting because for $31 \%$ of the sample, the membership to cured and uncured groups is latent. The issue of identification in mixture cure models has been discussed in the single-risk case (Farewell 1982; Yu et al. 2004), and recently in competing risks (Basu and Tiwari 2010). We take several steps to alleviate the identification issue. First, favoring parsimony over model complexity, the mixture survival functions defined here assume equal churn-specific hazards in the two groups. This solution imposes that the overall hazard is always lower in the cured group than in the uncured one, and was proposed by Basu and Tiwari (2010) ${ }^{7}$. Second, we assume homogeneity in effects of SLT customer behavior and marketing actions on customer SLT duration. This is not a strong assumption, since Kumar, Bhagwat, and Zhang (2015) did not find empirical support for customer heterogeneity in their model of SLT duration. Third, unlike previous studies (Sinha and Chandrashekaran 1992; Srinivasan, Lilien, and Rangaswamy 2006), we use separate variable sets for modeling the cure probability (Equation 2) and duration (Equation 1) to increase data variability and alleviate possible collinearity (demographic variables enter both equations). Lastly, we have collected a

\footnotetext{
${ }^{7}$ We also develop a version of the model that incorporates heterogeneity in the hazard rates in the Web Appendix.
} 
large sample to ensure that there are customers dropping-out in every period due to all reasons ${ }^{8}$. We have observed that estimating the model with poor starting points occasionally causes computational issues. Therefore, we estimate the simple models (M1 and M2) first, and use their solutions to initiate the estimation of the more complex models (M1X and M2X(L)). Finally, we simulate model parameters and are able to recover them with very little deviations.

\section{Addressing Endogeneity}

Firms strategically decide about the intensity of marketing variables to each customer $\mathrm{M}_{\mathrm{it}}=\left[\right.$ call2 $_{\mathrm{it}}$, email2 $\left._{\mathrm{it}}, \mathrm{dmail} 2_{\mathrm{it}}\right]$. Since we do not have the entire information about all inputs that go into this decision process, omitted variables may cause a correlation between marketing communications $\mathrm{M}_{\mathrm{it}}$ and the error term in the SLT churn equation. To address this endogeneity, we use a control function approach (Petrin and Train 2011), which depends on the quality of the instrumental variables (IVs). They should be related to the intensity of marketing communications but not influence the customer's decision to churn. We use three instruments: the average number of emails, direct mails, and phone calls made to customers' peers. We define peers as those customers who are in the same revenue bracket as the focal customer for the current period. Peer-based instruments have been used by German, Ebbes, and Grewal (2015) to investigate implications of CMO presence on the firm performance. We believe that the proposed IVs are relevant and valid. First, we argue that the level of marketing communications to peers is correlated with the level of marketing to the focal customer. Firms strategically set marketing variables to maximize profits, so marketing to the focal customer and peer customers, who are similar in generated revenue, will reflect this unobserved profit-maximizing rule. Therefore, the instruments are relevant. Regarding the validity of the IVs, we do not observe

\footnotetext{
${ }^{8}$ Since the model supports periods of different lengths, we have aggregated periods when no churn is observed. However, this happens only at the beginning of the time horizon.
} 
strong network effects, as the level of communications received by peers are not highly correlated $(\mathrm{r}<.10)$ with a customer's observed churn. Therefore, such communications are not observed by the focal customer and will not affect their decision to churn.

The control function approach requires that the endogenous variables $M_{i t}$ be written as a function of the instrumental variables, all exogenous variables entering the equation, and a vector of unobserved terms $\mu$. Under valid instruments, $\mu$ is the only source of endogeneity in the model. Therefore, we write the following equations:

$$
\begin{aligned}
& \text { [SLT_call } \left.{ }_{i t}, \text { SLT_email }_{\text {it }}, \text { SLT_dmail }_{\text {it }}\right] \\
& =\pi_{1, k} \text { AvgPcall }_{i t}+\pi_{2, k} \text { AvgPemail }_{i t}+\pi_{3, k} \text { AvgPdmail }_{i t} \\
& +\pi_{4, k} \text { AvgPcall }_{\text {it }} * \text { AvgPemail }_{\text {it }}+\pi_{5, k} \text { AvgPcall }_{\text {it }} * \text { AvgPdmail }_{\text {it }} \\
& +\pi_{6, k} \text { AvgPemail }_{\text {it }} * \text { AvgPdmail }_{i t}+\pi_{7, k} \text { SLT_revenue }_{\text {it }} \\
& +\pi_{8, k} \text { SLT_xbuy }_{i t}+\pi_{9, k} \text { SLT_xbuy }_{\text {it }}^{2}+\pi_{10, k} \text { SLT_refer }_{i t} \\
& +\pi_{11, k} \text { SLT_comp }_{i t}+\pi_{12, k} \text { SLT_reco }_{i t}+\pi_{13, k} \text { SLT_win_promo }_{i t} \\
& +\pi_{14, k} \text { taway }+\pi_{15, k} \text { taway }^{2}+\pi_{16, k} \text { FLT_tenure }+\pi_{17, k} \text { FLT_revenue } \\
& +\pi_{18, k} \text { gender }+\pi_{19, k} \text { age }+\pi_{20, k} \text { income }+\pi_{21, k} \text { hhold }+\pi_{22, k} \text { educ } \\
& +\mathrm{u}_{\mathrm{it}, \mathrm{k}} \text {, }
\end{aligned}
$$

where $\mathrm{k}=\{1,2,3\}$ indicates the endogenous dependent variables, and $\mathrm{Z}_{\mathrm{it}}=\left[\right.$ AvgPcall $\mathrm{it}_{\text {, }}$ AvgPemail $i_{i t}$ AvgPdmail $\left.{ }_{i t}\right]$ are the instrumental variables defined earlier. We discuss the OLS estimation results of Equation 3 in the Web Appendix, and provide more formal tests of the strength of the instruments. As a next step, the computed residuals $\left[\hat{u}_{i t, 1}, \hat{u}_{i t, 2}, \hat{u}_{i, t},\right]$ are introduced additively to Equation 1, which corrects the endogeneity issue due to omitted variables.

\section{RESULTS}

The proposed model is estimated using a maximum likelihood approach in Matlab 2016a software. We estimate all the supporting models starting from the simple competing risks model (M1), whose solution is later used to initiate the optimization of the mixture cure competing risks model (M2). In the next step, we estimate the models with time-varying covariates (M1X and M2X). The full model incorporates the cure predictors with the logit specification (Equation 2), 
and we refer to it as model M2XL. We report the results of model M2XL. The results of the supporting models as well as the estimation codes are available from the authors upon request.

To compare the performance of the estimated models, we compute the Akaike Information Criterion (AIC) and the Bayesian Information Criterion (BIC) ${ }^{9}$. Our estimation results support the mixture structure among returning customers, as evidenced by the AIC values $\left(\mathrm{AIC}_{\mathrm{M} 2}=13566.12\right.$ vs. $\left.\mathrm{AIC}_{\mathrm{M} 1}=13718.54\right)$, indicating a better fit of model M2 over M1. This suggests that issues underlying the FLT churn can be rectified, so that a group of returning customers is not susceptible to a related SLT churn. Moreover, explanatory covariates related multiplicatively to customer hazard rate, as well as cure status predictors, offer additional insights, as indicated by the improvement in AIC values for our proposed model $\left(\mathrm{AIC}_{\mathrm{M} 2 \mathrm{XL}}=52948.32\right.$ vs. $\mathrm{AIC}_{\mathrm{M} 2 \mathrm{X}}=60336.98$ vs. $\left.\mathrm{AIC}_{\mathrm{M} 1 \mathrm{X}}=71724.52\right)$. Adjusting for model complexity, the BIC values also support these findings.

We now turn our focus to estimation results of the proposed model M2XL shown in Table 5. Overall, the Weibull shape parameter estimates are significantly greater than one across all FLT and SLT churn risks, indicating a positive time dependence of the risk of defection over the SLT. That is, customers' risk of churning is consistently increasing over time, and this applies to all three SLT defection reason combinations. Previous research in CRM has recognized that hazard rates increase over time in a customer's FLT (Braun and Schweidel 2011), and our findings suggest that this also applies in the SLT. An examination of the effect of the time-varying SLT customer behavior and marketing communications on the duration of the second tenure, reveals some additional, interesting insights. Each coefficient summarizes the

\footnotetext{
${ }^{9}$ Note that the likelihood of the model without covariates cannot be directly compared to the one including covariates, since the former is estimated on less informative data (cross-sectional), while the latter includes monthly time-varying covariates (panel-data structure obtained by dividing the time horizon into monthly intervals). Since the models are equivalent and explain the same time dependence structure, the estimates of the Weibull parameters should be similar.
} 
proportionate response of the hazard to a small change in the relevant covariate. Therefore, the negative (positive) parameters indicate that an increase in a covariate proportionally leads to decreased (increased) churn rates, which translates to longer (shorter) SLT durations.

--- Insert Table 5 about here ---

Consistent with our expectations, we find that customers bringing more SLT revenue exhibit longer SLT tenures $\left(\beta_{1}=-.057\right.$, $p$-value $\left.<.01\right)$, meaning that loyal customers pay on average higher prices (indicating higher perceived value). Regarding customer behavior, we see that customers who engage in traditionally desirable behaviors, like cross-buying $\left(\beta_{2}=-.076\right.$, pvalue $<.01 ; \beta_{3}=.009$, $p$-value $\left.<.05\right)$ and customer referrals $\left(\beta_{4}=-.061\right.$, $p$-value $\left.<.05\right)$, also exhibit longer SLT tenures. On the other hand, customers who file more complaints $\left(\beta_{5}=.004\right.$, pvalue <.05) will have shorter SLT. Analyzing the firm's actions, we find that increased service recovery efforts ( $\beta_{6}=-.021, \mathrm{p}$-value $\left.<.05\right)$ have a positive association with the duration of customers' SLT, in line with our expectations. The same applies to marketing contacts, both for the main effects $\left(\beta_{7}=-1.823\right.$, p-value $<.01 ; \beta_{8}=-1.471$, p-value $<.01 ; \beta_{9}=-2.196$, $p$-value $\left.<.01\right)$ and the interactions ( $\beta_{10}=-.044, p$-value $<.05 ; \beta_{11}=-.039$, $p$-value $<.05 ; \beta_{12}=-.012$, $p$-value $\left.<.10\right)$. We also find that the risk of repeat churning is significantly lower while the promotional offer perks are active $\left(\beta_{13}=-.401, \mathrm{p}\right.$-value $\left.<.05\right)$, as expected. Regarding prior churn behavior, the results indicate that the duration of the lapse period has a nonlinear relationship with the second tenure with the firm ( $\beta_{14}=.081, \mathrm{p}$-value $<.01 ; \beta_{15}=-.036$, $\mathrm{p}$-value $\left.<.05\right)$, so that customers who accept the win-back offer early exhibit longer second tenures. Based on the estimates for the FLT tenure $\left(\beta_{16}=-.057, \mathrm{p}\right.$-value $\left.<.05\right)$ and revenue $\left(\beta_{17}=-.039, \mathrm{p}\right.$-value $\left.<.05\right)$ controls, we find evidence that customers with longer and more profitable FLTs will also tend to have longer SLTs. Looking at customers' demographics, we find that female customers ( $\beta_{18}=.018$, p-value $\left.<.05\right)$, older 
customers $\left(\beta_{19}=-.062, p\right.$-value $\left.<.10\right)$, and those with higher incomes $\left(\beta_{20}=-.155, p\right.$-value $\left.<.05\right)$ and levels of education $\left(\beta_{22}=-.065\right.$, $\mathrm{p}$-value $\left.<.05\right)$ are associated with longer SLT durations.

Regarding customers' membership in the cured and uncured groups, Table 5 shows the estimated effects of the FLT, demographic, and win-back predictors on the probability of being cured. Positive coefficients are associated with an increase in the likelihood of a customer being cured, while negative coefficients show the opposite effect. The direction of the effects is uniform across the different FLT churn reasons and is largely consistent with our expectations. Specifically, customers with longer tenures, and higher generated revenues during the FLT are more likely to become cured. The same applies to customers who made more successful FLT referrals. On the contrary, higher numbers of complaints decrease the chances of a customer being a member of the cured group, while service recoveries can successfully increase them. Marketing communications during the customer's FLT also have a positive relationship with their cure likelihood. This effect is enhanced when such actions are implemented through various media, as evidenced by the interactions between them. Regarding demographics, customers who are female, are older, have larger household size, and have higher income and level of education are more likely to be cured. The direction of the effects of the abovementioned characteristics and actions apply universally, regardless of the reason for the FLT churn. Finally, win-back offers including solely price incentives are associated with higher cure probabilities for customers whose FLT churn was price-related (i.e. price or price-and-service). On the other hand, customers who left only because of service issues are more likely to be cured when accepting an offer including solely service incentives.

Based on the estimates of cure predictors reported in Table 5, we have calculated the average probability for those customers to be price-cured (15.3\%) and service-cured (20.4\%), 
suggesting that that the firm has most success in addressing service issues. The propensity for customers to be both price-cured and service-cured is naturally the lowest (6.2\%), as the model implies that they would never churn in their SLT. Model-free evidence provides support for this result. Since only censored observations can be potentially both price-cured and service-cured, the upper bound on this quantity is $9.94 \%$. In other words, returning customers whose FLT churn was due to price-and-service and SLT duration is longer than four years (length of the observation window) have a high chance of being long-term customers (around 62\%). --- Insert Figure 3 about here ---

To capture time dependence in customers' repeat churn behavior, we use the average predicted cure probabilities and Weibull estimates to plot relevant cause-specific SLT survival functions. Figures 3(a-b) show two types of survival functions: an aggregate one, specific to churn categories with common elements with the FLT churn (solid line), and a survival function specific to the churn category without common elements with the FLT churn (dashed). The general expressions for these functions are derived in the Web Appendix. The survival function in Figure $3 \mathrm{c}$ aggregates all types of churn categories. The average predicted cure probabilities are visible here as the values at which the solid lines level off. Focusing on customers whose FLT churn was attributed to a price reason, price issues are still the main cause for early SLT churn, as evidenced by the solid survival curve that drops the fastest before leveling off (see panel (a) in Figure 3). This suggests that customers who churn early will do so because of price-related reasons again, despite the firm's efforts to reacquire and cure them. However, the longer a returning customer maintains the contract, the more likely they will churn for reasons other than price. A similar pattern is visible for customers who churned because of a service reason in their FLT (see panel (b) in Figure 3). In this case, service-related concerns cause the customers to 
repeat churn earlier than non-service-related concerns. Finally, customers whose FLT churn was because of both reasons exhibit a unique survival pattern (see panel (c) in Figure 3), which drops quickly, but levels off earlier than the previous cases. Overall, we see that price- and servicechurners with short SLT tenures are more likely to churn again due to the same reason as in the FLT, suggesting that their initial concerns about the service offering remain unchanged.

\section{Model validation}

Since the focus of this study is on the time and the reason for SLT churn, we examine two related quantities for model validation: we compare the model-based predictions with the observed values for (a) retention rates and (b) proportions of churn reasons. The retention rate captures the aggregate churn pattern regardless of the reason. Evaluated in month $t$, it is the ratio of customers who maintained service throughout month $t$ over those who maintained service throughout month $\mathrm{t}-1$, calculated as the fraction of two consecutive survival functions $\mathrm{S}(\mathrm{t}) / \mathrm{S}(\mathrm{t}-$ 1). Those are calculated separately for each model, as they have different survival function specifications. To assess how well the model predicts the type of churn, we first calculate the observed proportions of customers churning for each reason every month. The predicted relative churn probability of reason $j$ in month $t$ is the proportion of the churn-specific risk in the overall churn risk. Based on the relation between the integrated hazard and the survival function, we define it as $-\log S_{\mathrm{j}}(\mathrm{t}) /-\Sigma_{\mathrm{l}} \log \mathrm{S}_{\mathrm{l}}(\mathrm{t})$, where $\mathrm{S}_{\mathrm{j}}$ is the churn-specific survival function.

To validate the proposed model (M2XL) we use the calibration and a holdout sample to gauge both in- and out-of-sample predictive performance, and compare it with the simpler benchmarks (M1 $(\mathrm{X})$ and $\mathrm{M} 2(\mathrm{X}))$. To this end, we calculate the mean absolute percentage error (MAPE) for both the calibration and the holdout sample, comparing the differences between predicted and observed values. Overall, the prediction errors of the retention rates are small (less than $5 \%$ for all models in the calibration and holdout sample), with the proposed approach 
yielding the most accurate forecasts. The prediction errors for the proportions of churn reasons range from $16.86 \%$ (M2XL) to $24.37 \%$ (M1) in the holdout sample, and from $15.46 \%$ (M2XL) to $22.27 \%$ (M1) in the calibration sample. The findings regarding the out-of-sample predictions suggest that the inclusion of covariates in the SLT hazard and the logit probabilities leads to improved accuracy, as they capture important firm and customer behavior. Detailed results are provided in the Web Appendix.

\section{Simulation}

We demonstrate how a firm can utilize the proposed approach and provide evaluations of simulated marketing policies in terms of their retention and monetary gains. To this end, we perform simulations of two types of scenarios, using the estimated results of our proposed model. First, we evaluate the cure probability of customer profiles based on their FLT history and the type of win-back they received, and then compare gains (losses) obtained from a longer (shorter) SLT tenure. Second, we explore how SLT marketing retention efforts can extend the SLT duration. In each scenario, we compute separately the median duration and profitability of customers whose FLT churn was due to price, service, and both reasons, which are shown in the columns of Table 6 . The median duration is the point $t$ where the survival probability is $\mathrm{S}(\mathrm{t})=$ 0.5 . In other words, $50 \%$ of the population would have shorter tenures than the median value, and the other 50\% will have longer tenures. To calculate profitability, we assume an average monthly revenue of $\$ 100$ from each customer, and a profit margin of $18 \%$ (after the operational and marketing costs), which are representative for this industry.

The benchmark policy is one where all covariates are fixed at median values (Equation 1 and 2). The median SLT duration and customer value of this benchmark policy is shown in the first row of Table 6, and all incremental gains per customer obtained from different policy simulations are relative to the gains from the benchmark policy. We find that the median SLT 
duration of the benchmark policy amounts to 1,079 days for customers who churned for a price reason in their FLT, 1,103 days for service churners, and 1,685 for customers who churned due to both reasons. The median SLT profitability for the benchmark policy ranges at $\$ 647-\$ 1101$. The results of the last category (FLT churn due to price-and-service) need to be read with caution. By construction, the benchmark cure probability is $50 \%$, achievable only when at least $50 \%$ of the sample is censored (vs. $9.94 \%$ in the current application). Furthermore, due to the specific shape of the survival function (Figure 3c) the median duration is not specified for cure probabilities higher than $50 \%$ (it would never reach the value $S(t)=0.5$ ). The results of the various policy simulations are summarized in the remaining rows of Table 6 .

--- Insert Table 6 about here ---

The cure-probability-based simulations show how customer characteristics - like FLT tenure and revenue - and win-back offer allocation are related to the customer cure probability, and in turn SLT duration and profitability. When a customer accepts the win-back offer, the firm has information about their FLT and churn behavior, and is able to calculate the probability the customer is cured. Profiling customers based on their FLT tenure, we see that a customer who is in the bottom $25 \%$ percentile of the FLT tenure distribution and whose FLT reason for churn was price-related will have a $5 \%$ probability of cure, a median tenure of 1,022 days, and will bring a loss of \$34 compared to a benchmark customer. Based on customer cure profiling, the biggest monetary gains, amounting to $\$ 55.80$, come from customers whose FLT churn was service-based and have longer FLT tenures (at the top $25 \%$ percentile). Furthermore, we find that the bundled win-back offer generally leads to a higher cure probability, and in turn longer tenure and higher profits, than single-benefit offers (even when the benefit matches the cause for FLT churn). This 
suggests that customers receiving a win-back offer with two perks may perceive it as more valuable than the single-benefit offers, even though all win-back offers are comparable in value.

Regarding the SLT marketing strategy simulations, we consider the following actionable policies that the firm can implement during the SLT: increasing successful recoveries and increasing the number of phone calls, emails, and direct mails per year. We found that improving successful recoveries has minimal impact on median SLT duration and profitability, up to $\$ 0.60$ per customer. In contrast, the monetary gains from marketing communication adjustments are much greater, with the biggest improvement achieved by increasing the number of direct mails sent to the customer. If the firm sends one additional paper communication to retain its customers, the SLT monetary gains could range at $\$ 15-18$ per customer. Implementing this policy over the entire sample would lead to incremental gains of $\$ 150,000$ over the customers' SLT. For a firm that loses a million customers due to second churn every quarter, the overall incremental gains can result in increasing the SLT profitability by more than $\$ 15$ million.

\section{DISCUSSION}

This research investigates the SLT of returning customers in order to enhance retention strategies. Using a novel modeling approach to handle the intricacies of the SLT, we study customers' SLT churn behavior, which includes the timing and reason for such churn. Our findings suggest that customers' defection motives are not consistent, as the reasons for FLT and SLT churn are generally different, and exhibit varying time-dependence. Specifically, among the customers who lapsed because of price (service) concerns in the FLT, those who terminate their SLT early tend to churn due to price (service) again. In contrast, those who terminate their SLT later on are more likely to churn because of other reasons, suggesting that customers' churn patterns change over time. We measure the effect of contemporary customer behavior and 
marketing activities on the SLT duration and repeat churn behavior, and find that overall customers' positive SLT experience is related to longer SLT tenures. Furthermore, firm-initiated contacts are the backbone of a retention strategy in the SLT, showing an ability to substantially extend tenures and consequently bring profit. We find evidence that there are two types of returning consumers. The first group is composed of individuals who can defect due to any reason (uncured customers), and the other includes individuals who are susceptible to fewer types of churn (cured customers) because they are satisfied by the firm's efforts to improve aspects of the service. Griffin and Lowenstein (2001) recommend developing internal criteria for a routine segmentation of customers based on their reacquisition probability and expected SLTV. We further recommend refining such segmentation criteria by accounting for customers' cure probability, which we show impacts their SLT profitability as well.

\section{Managerial Implications}

Our findings enable managers to design retention strategies for the SLT based on the relation of customer-specific behaviors and marketing activities with the SLT duration and repeat churn behavior. Thus, we offer a tool to track in real time which customers are at risk of churning again, when, and why. Using current data allows the firm to build proactive retention strategies aimed at customers who are most at risk of churning again and intervene at the right time in their SLT. Our findings suggest that marketing communications through a variety of media can extend customers' SLT. This research also aids in segmentation of returning customers based on their cure potential. By incorporating the cure predictors, it enables the firm to leverage its knowledge about customers' FLT and recognize which reacquired customers have a high potential of becoming long-term customers. Naturally, firms want to make the most out of their reacquisition efforts, and we show that responding to and amending the issues that led to FLT churn can convert lost customers not only to reacquired but also cured customers. 


\section{Limitations and Future Research}

We recognize that our findings are subject to a few limitations, and our research can be extended in several directions. The framework can accommodate any number of unique event types, but we advise caution in high-dimensional problems, as the model exhibits exponential complexity. Planning the research, one should first conceptualize which event types are mutually exclusive, and group similar motives. Complexity issues can be alleviated by redefining the rules on the risk sets to restrict unfeasible combinations, or to focus on two-element combinations only. We also take the perspective of a single firm, and therefore cannot control for competitive actions or for customers' behavior during lapse period. Neither do we observe reasons why customers come back besides the firm's efforts. We assume there is a degree of opportunism driving their return decisions, which can be lower for cured customers. However, this reflects the information that managers have at their disposal when a customer is reacquired.

Due to data limitations, we are not able to estimate the individual influence of price and service churn because the third type of churn is a combination of the two. Also, win-back offers are standardized for all customers, which prevents us from testing incentive variations extensively. Potentially, firms can tailor the offers based on each customer's CLV, and the current research does not examine whether there is a differential impact on their SLT. Additionally, churn decisions may depend on the service usage, causing endogeneity in the consumer behavior. Future research could examine this issue by interacting relevant consumer behavior variables with time. The model could also include SLT variables as cure predictors. Finally, our model could be used in applications with heterogeneity in hazard parameters across the two groups (as illustrated in the Web Appendix). Being mindful of the abovementioned limitations, we can still gain valuable insights into customers' repeat churn behavior. 


\section{REFERENCES}

Basu, Sanjib and Ram C. Tiwari (2010), "Breast Cancer Survival, Competing Risks and Mixture Cure Model: A Bayesian Analysis," Journal of the Royal Statistical Society: Series A (Statistics in Society), 173 (2), 307-29.

Berkson, Joseph and Robert P. Gage (1952), "Survival Curve for Cancer Patients Following Treatment," Journal of the American Statistical Association, 47 (259), 501-15.

Biyalogorsky, Eyal, Eitan Gerstner, and Barak Libai (2001), "Customer Referral Management: Optimal Reward Programs," Marketing Science, 20 (1), 82-95.

Bogomolova, Svetlana (2010), "Life After Death? Analyzing Post-Defection Consumer Brand Equity," Journal of Business Research, 63 (11), 1135-41.

Bolton, Ruth N. (1998), “A Dynamic Model of the Duration of the Customer's Relationship with a Continuous Service Provider: The Role of Satisfaction," Marketing Science, 17 (1), $45-65$.

Braun, Michael and David A. Schweidel (2011), "Modeling Customer Lifetimes with Multiple Causes of Churn," Marketing Science, 30 (5), 881-902.

Farewell, Vernon T. (1982), "The Use of Mixture Models for the Analysis of Survival Data with Long-Term Survivors," Biometrics, 38 (4), 1041-46.

Germann, Frank, Peter Ebbes, and Rajdeep Grewal (2015), "The Chief Marketing Officer Matters!," Journal of Marketing, 79 (3), 1-22.

Griffin, Jill and Michael W. Lowenstein (2001), Customer Winback: How to Recapture Lost Customers--And Keep Them Loyal. San Francisco: Jossey-Bass, Inc. Publishers.

Homburg, Christian, Wayne D. Hoyer, and Ruth Maria Stock (2007), "How to Get Lost Customers Back?," Journal of the Academy of Marketing Science, 35 (4), 461-74. 
Kalbfleisch, John D., and Ross L. Prentice (2002), The Statistical Analysis of Failure Time Data (2nd ed.): John Wiley \& Sons, Inc.

Keaveney, Susan M. (1995), "Customer Switching Behavior in Service Industries: An Exploratory Study," Journal of Marketing, 59 (2), 71-82.

Kumar, V., Yashoda Bhagwat, and Xi Zhang (2015), "Regaining "Lost" Customers: The Predictive Power of First-Lifetime Behavior, the Reason for Defection, and the Nature of the Win-Back Offer," Journal of Marketing, 79 (4), 34-55.

Kumar, V., Xi Zhang, and Anita Luo (2014), "Modeling Customer Opt-In and Opt-Out in a Permission-Based Marketing Context," Journal of Marketing Research, 51 (4), 403-19. Larson, Martin G. and Gregg E. Dinse (1985), "A Mixture Model for the Regression Analysis of Competing Risks Data," Journal of the Royal Statistical Society. Series C (Applied Statistics), 34 (3), pp. 201-11.

Petrin, Amil and Kenneth Train (2010), "A Control Function Approach to Endogeneity in Consumer Choice Models," Journal of Marketing Research, 47 (1), 3-13.

Reinartz, Werner, Manfred Krafft, and Wayne D. Hoyer (2004), "The Customer Relationship Management Process: Its Measurement and Impact on Performance," Journal of Marketing Research, 41 (3), 293-305.

Reinartz, Werner and V. Kumar (2003), "The Impact of Customer Relationship Characteristics on Profitable Lifetime Duration," Journal of Marketing, 67 (1), 77-99.

Reinartz, Werner, Jacquelyn S. Thomas, and V. Kumar (2005), "Balancing Acquisition and Retention Resources to Maximize Customer Profitability," Journal of Marketing, 69 (1), 6379. 
Seetharaman, P. B. and Pradeep K. Chintagunta (2003), "The Proportional Hazard Model for Purchase Timing: A Comparison of Alternative Specifications," Journal of Business \& Economic Statistics, 21 (3), 368-82.

Sinha, Rajiv K. and Murali Chandrashekaran (1992), "A Split Hazard Model for Analyzing the Diffusion of Innovations," Journal of Marketing Research, 29 (1), 116-27.

Srinivasan, Raji, Gary L. Lilien, and Arvind Rangaswamy (2006), "The Emergence of Dominant Designs," Journal of Marketing, 70 (2), 1-17.

Stauss, Bernd and Christian Friege (1999), "Regaining Service Customers: Costs and Benefits of Regain Management," Journal of Service Research, 1 (4), 347-61.

Thomas, Jacquelyn S., Robert C. Blattberg, and Edward J. Fox (2004), "Recapturing Lost Customers," Journal of Marketing Research, 41 (1), 31-45.

Tokman, Mert, Lenita M. Davis, and Katherine N. Lemon (2007), "The WOW Factor: Creating Value through Win-Back Offers to Reacquire Lost Customers," Journal of Retailing, 83 (1), 47-64.

T-Mobile (2017), “There's Never Been a Better Time to Switch to T-Mobile," (accessed April 16, 2016), [available at: http://www.t-mobile.com/offer/switch-carriers-no-earlytermination-fee.html].

Verizon (2017), "Switch to Verizon and Get up to \$650," (accessed April 16, 2016), [available at: http://www.verizonwireless.com/promos/switch-and-save/]. Yu, Binbing, Ram C. Tiwari, Kathleen A. Cronin, and Eric J. Feuer (2004), "Cure Fraction Estimation from the Mixture Cure Models for Grouped Survival Data," Statistics in Medicine, 23 (11), 1733-1747. 
TABLES AND FIGURES

TABLE 1: SELECT EMPIRICAL STUDIES MODELING CUSTOMER DEFECTION AND/OR REACQUISITION IN CONTRACTUAL SETTINGS

\begin{tabular}{|c|c|c|c|c|c|c|c|c|}
\hline & SLT DV & $\begin{array}{l}\text { SLT (FLT) } \\
\text { Multiple } \\
\text { defection } \\
\text { reasons }\end{array}$ & SLT IVs & $\begin{array}{l}\text { Win- } \\
\text { back }\end{array}$ & $\begin{array}{l}\text { Time- } \\
\text { varying } \\
\text { CB }\end{array}$ & $\begin{array}{l}\text { Modelling } \\
\text { approach }\end{array}$ & Industry & Contributions/ benefits \\
\hline $\begin{array}{l}\text { Thomas, } \\
\text { Blattberg, } \\
\text { and Fox } \\
(2004)\end{array}$ & & $\mathrm{N}(\mathrm{N})$ & & & $\mathrm{N}$ & $\begin{array}{l}\text { Split hazard } \\
\text { model }\end{array}$ & Newspaper & $\begin{array}{l}\text { Develop optimal pricing for } \\
\text { reacquisition and SLT to } \\
\text { maximize SLT value }\end{array}$ \\
\hline $\begin{array}{l}\text { Homburg, } \\
\text { Hoyer, and } \\
\text { Stock (2007) }\end{array}$ & $\mathrm{N}$ & $\mathrm{N}(\mathrm{N})$ & $\mathrm{N}$ & & $\mathrm{N}$ & SEM, logit & $\begin{array}{l}\text { Telecommunication } \\
\text { services }\end{array}$ & $\begin{array}{l}\text { Find drivers of customers' } \\
\text { revival-specific satisfaction } \\
\text { and probability of } \\
\text { reacquisition }\end{array}$ \\
\hline $\begin{array}{l}\text { Braun and } \\
\text { Schweidel } \\
(2011)\end{array}$ & $\mathrm{N}$ & & $\mathrm{N}$ & $\mathrm{N}$ & $\mathrm{N}$ & $\begin{array}{l}\text { Hierarchical } \\
\text { competing } \\
\text { risks model }\end{array}$ & $\begin{array}{l}\text { Telecommunication } \\
\text { services }\end{array}$ & $\begin{array}{l}\text { Predict FLT duration and } \\
\text { probability to churn due to } \\
\text { different reasons based on } \\
\text { geo-demographic data }\end{array}$ \\
\hline $\begin{array}{l}\text { Kumar, } \\
\text { Bhagwat, and } \\
\text { Zhang (2015) }\end{array}$ & & $\mathrm{N}$ & $\mathrm{N}$ & & $\mathrm{N}$ & $\begin{array}{l}\text { Censored } \\
\text { Tobit model } \\
\text { with probit } \\
\text { selection }\end{array}$ & $\begin{array}{l}\text { Telecommunication } \\
\text { services }\end{array}$ & $\begin{array}{l}\text { Predict the relation between } \\
\text { SLT profitability and customer } \\
\text { information: FLT customer } \\
\text { behavior, reason for defection, } \\
\text { and win-back offer }\end{array}$ \\
\hline $\begin{array}{l}\text { THIS } \\
\text { PAPER }\end{array}$ & & & & & & $\begin{array}{l}\text { Mixture cure } \\
\text { competing risk } \\
\text { model }\end{array}$ & $\begin{array}{l}\text { Telecommunication } \\
\text { services }\end{array}$ & $\begin{array}{l}\text { Estimate jointly the SLT } \\
\text { duration and the probability to } \\
\text { repeat churn due to multiple } \\
\text { defection reasons, accounting } \\
\text { for a fraction of cured } \\
\text { customers }\end{array}$ \\
\hline
\end{tabular}

${ }^{1}$ As an explanatory variable. 


\section{TABLE 2: OPERATIONALIZATION OF VARIABLES}

\begin{tabular}{|c|c|c|}
\hline Variable & Abbreviation $^{1}$ & Operationalization \\
\hline \multicolumn{3}{|c|}{ SLT $^{2}$ Variables (Varying by Month) } \\
\hline SLT Revenue & SLT_revenue & The monthly revenue generated by the customer in dollars \\
\hline SLT Cross-buy & SLT_xbuy & The number of different service categories the customer is subscribed to \\
\hline SLT Referrals & SLT_refer & The number of customer referrals brought to the firm by the customer \\
\hline SLT Complaints & SLT_comp & The number of complaints made by the customer \\
\hline SLT Recoveries & SLT_reco & The number of service recoveries the firm completed for the customer \\
\hline SLT Phone calls & SLT_call & The number of phone calls made by the firm to the customer \\
\hline SLT Emails & SLT_email & The number of emails sent by the firm to the customer \\
\hline SLT Direct mails & SLT_dmail & The number of direct mails sent by the firm to the customer \\
\hline SLT Promotion & $\begin{array}{l}\text { SLT_win_- } \\
\text { promo }\end{array}$ & $\begin{array}{l}\text { An indicator of whether the promotion offered in the win-back is active } \\
(1=\text { active, } 0=\text { inactive) }\end{array}$ \\
\hline \multicolumn{3}{|c|}{ FLT ${ }^{3}$ and Demographic Variables (Time-Invariant) } \\
\hline FLT Churn & & $\begin{array}{l}\text { Categorical variable indicating: } 1 \text { - a price related reason, } 2 \text { - service } \\
\text { related reason, } 3 \text { - price and service related reason. }\end{array}$ \\
\hline $\begin{array}{l}\text { FLT Defection } \\
\text { period }\end{array}$ & taway & $\begin{array}{l}\text { The number of days from the time the customer defected until he or she } \\
\text { was reacquired by the firm (i.e., the period between the FLT and SLT) }\end{array}$ \\
\hline FLT Tenure & FLT_tenure & $\begin{array}{l}\text { The number of days the customer retained service with the firm prior to the } \\
\text { first defection (i.e., the duration of the FLT) }\end{array}$ \\
\hline FLT Revenue & FLT_revenue & $\begin{array}{l}\text { The average monthly revenue generated by the customer during the FLT in } \\
\text { dollars }\end{array}$ \\
\hline FLT Cross-buy & FLT_xbuy & $\begin{array}{l}\text { The total number of different service categories the customer was } \\
\text { subscribed to during the FLT }\end{array}$ \\
\hline FLT Referrals & FLT_refer & The average number of yearly referrals by the customer in the FLT \\
\hline FLT Complaints & FLT_comp & The average number of yearly complaints made by the customer in the FLT \\
\hline FLT Recoveries & FLT_reco & $\begin{array}{l}\text { The average number of yearly service recoveries the firm completed for the } \\
\text { customer in the FLT }\end{array}$ \\
\hline FLT Phone calls & FLT_call & $\begin{array}{l}\text { The average number of yearly phone calls made by the firm to the customer } \\
\text { in the FLT }\end{array}$ \\
\hline FLT Emails & FLT_email & $\begin{array}{l}\text { The average number of yearly emails sent by the firm to the customer in the } \\
\text { FLT }\end{array}$ \\
\hline FLT Direct mails & FLT_dmail & $\begin{array}{l}\text { The average number of yearly direct mails sent by the firm to the customer } \\
\text { in the FLT }\end{array}$ \\
\hline Gender & gender & An indicator of the customer's gender $(1=$ male, $0=$ female $)$ \\
\hline Age & age & The customer's age in years \\
\hline Income & income & The customer's household income in dollars \\
\hline Household size & hhold & The number of people in the customer's household \\
\hline Education & educ & The customer' highest attained education level in years \\
\hline \multicolumn{3}{|c|}{ Dependent Variables } \\
\hline SLT Duration & & $\begin{array}{l}\text { The number of days the customer retained service with the firm after } \\
\text { reacquisition divided into non-overlapping monthly intervals }\end{array}$ \\
\hline SLT Churn & & $\begin{array}{l}\text { Categorical variable indicating: } 0 \text { - no churn, } 1 \text { - a price related reason, } 2- \\
\text { service related reason, } 3 \text { - price and service related reason. }\end{array}$ \\
\hline
\end{tabular}


TABLE 3: DESCRIPTIVE STATISTICS

\begin{tabular}{lcc}
\hline SLT Variables & Mean & Std. Dev. \\
\hline SLT Revenue (per month in dollars) & 97.62 & 25.8 \\
SLT Cross-buy & 1.730 & .47 \\
SLT Referrals (per month) & .079 & .11 \\
SLT Complaints (per month) & .014 & .14 \\
SLT Recoveries (per month) & .005 & .08 \\
SLT Phone calls (per month) & .076 & .03 \\
SLT Emails (per month) & .510 & .41 \\
SLT Direct mails (per month) & .320 & .45 \\
SLT Promotion (per month) & .156 & .36 \\
\hline FLT and Demographic Variables & Mean & Std. Dev. \\
\hline FLT Defection period (in days) & 108.7 & 19.8 \\
FLT Tenure (in days) & 1427.3 & 109.2 \\
FLT Revenue (per month in dollars) & 85.80 & 15.3 \\
FLT Cross-buy & 1.560 & .47 \\
FLT Referrals (per year) & .090 & .04 \\
FLT Complaints (per year) & .100 & .04 \\
FLT Recoveries (per year) & .067 & .03 \\
FLT Phone calls (per year) & .780 & .33 \\
FLT Emails (per year) & 3.960 & .64 \\
FLT Direct mails (per year) & 2.510 & .42 \\
Gender (\% male) & $57.4 \%$ & .47 \\
Age & 39.90 & 9.56 \\
Income (in dollars) & $98,116.40$ & $23,691.40$ \\
Household size & 2.910 & 1.25 \\
Education (in years) & 16.01 & 2.18 \\
\hline Dependent Variables & Mean & Std. Dev. \\
\hline SLT Duration (in days) & 1352.4 & 110.7 \\
\hline N=7,054 customers & & \\
& & \\
\hline
\end{tabular}


TABLE 4: CUSTOMERS' CHURN REASON IN THE FLT VS. SLT

\begin{tabular}{lccccc}
\hline & & \multicolumn{4}{c}{ SLT Churn Reason } \\
FLT Churn Reason & No churn & Price & Service & Price \& Service & Total \\
\hline Price & $248^{*}$ & 683 & $712^{*}$ & 677 & 2320 \\
Service & $265^{*}$ & $740^{*}$ & 692 & 733 & 2430 \\
Price \& Service & $229^{*}$ & 683 & 720 & 672 & 2304 \\
Total & 742 & 2106 & 2124 & 2082 & 7054 \\
\hline${ }^{*}$ Latent cure status & & \multicolumn{4}{c}{} \\
\hline
\end{tabular}


TABLE 5: PROPOSED MODEL ESTIMATION RESULTS

\begin{tabular}{|c|c|c|c|}
\hline & \multicolumn{3}{|c|}{ FLT Churn: } \\
\hline & Price & Service & $\begin{array}{l}\text { Price \& } \\
\text { Service }\end{array}$ \\
\hline \multicolumn{4}{|c|}{ Mixture Cure - Predictors } \\
\hline FLT Tenure & $.041 * *$ & $.084 * *$ & $.027 * *$ \\
\hline FLT Revenue & $.029 * *$ & $.089 * *$ & $.009 * *$ \\
\hline FLT Cross-buy & $.922 * *$ & $.126^{* *}$ & $.082 * *$ \\
\hline FLT Cross-buy ${ }^{2}$ & $-.317 * *$ & $-.019 * *$ & $-.119 *$ \\
\hline FLT Referrals & $.045^{* *}$ & $.079 * *$ & $.021 * *$ \\
\hline FLT Complaints & $-.077 * *$ & $-.142 * *$ & $-.028 * *$ \\
\hline FLT Recoveries & $.059 * *$ & $.031 * *$ & $.007 * *$ \\
\hline FLT Phone calls & $.388 * * *$ & $.066^{* * *}$ & $.046 * * *$ \\
\hline FLT Emails & $.291 * * *$ & $.091 * * *$ & $.058 * * *$ \\
\hline FLT Direct mails & $.177 * * *$ & $.143 * * *$ & $.043 * * *$ \\
\hline \multicolumn{4}{|l|}{ FLT Emails } \\
\hline \multicolumn{4}{|l|}{ FLT Direct mails } \\
\hline $\begin{array}{l}\text { FLT Emails * } \\
\text { FLT Direct mails }\end{array}$ & $.346^{* *}$ & $.046^{* *}$ & $.035^{* *}$ \\
\hline Gender & $-.093 * *$ & $-.027 * *$ & $-.052 * *$ \\
\hline Age & $.002 *$ & $.041 *$ & .001 \\
\hline Income & $.084 * *$ & $.042 * *$ & $.003 *$ \\
\hline Household size & $.093^{*}$ & $.087 *$ & $.025^{*}$ \\
\hline Education & $.004 *$ & $.058 *$ & $.018 * *$ \\
\hline $\begin{array}{l}\text { Price-related } \\
\text { win-back }\end{array}$ & $.052 * *$ & $.029 * *$ & $.092 * *$ \\
\hline $\begin{array}{l}\text { Service-related } \\
\text { win-back }\end{array}$ & $.027 * *$ & $.043 * *$ & $-.075 * *$ \\
\hline \multicolumn{4}{|c|}{ Competing Risks - Weibull Parameters } \\
\hline \multicolumn{4}{|c|}{ SLT Churn: Price } \\
\hline Scale & $.215^{* * *}$ & $.196 * * *$ & $.188 * * *$ \\
\hline Shape & $7.417 * * *$ & $8.922 * * *$ & $8.865^{* * *}$ \\
\hline \multicolumn{4}{|c|}{ SLT Churn: Service } \\
\hline Scale & $.191 * * *$ & $.168 * * *$ & $.153 * * *$ \\
\hline Shape & $7.186 * * *$ & $8.417 * * *$ & $8.893 * * *$ \\
\hline \multicolumn{4}{|c|}{ SLT Churn: Price \& Service } \\
\hline Scale & $.198 * * *$ & $.147 * * *$ & $.139 * *$ \\
\hline Shape & $7.023 * * *$ & $8.785 * * *$ & $8.927 * * *$ \\
\hline
\end{tabular}


TABLE 6: THE IMPACT OF REDUCED REPEAT CHURN BEHAVIOR ON DURATION AND PROFITABILITY

\begin{tabular}{|c|c|c|c|c|c|c|c|c|c|}
\hline & \multicolumn{3}{|c|}{ FLT: Price } & \multicolumn{3}{|c|}{ FLT: Service } & \multicolumn{3}{|c|}{ FLT: Price \& Service ${ }^{3}$} \\
\hline & $\%$ cured & $\begin{array}{c}\text { Median } \\
\text { Duration } \\
\text { (days) }\end{array}$ & $\begin{array}{c}\text { Incremental } \\
\text { Profit per } \\
\text { Customer }^{2}(\$)\end{array}$ & $\%$ cured & $\begin{array}{c}\text { Median } \\
\text { Duration } \\
\text { (days) }\end{array}$ & $\begin{array}{c}\text { Incremental } \\
\text { Profit per } \\
\text { Customer }^{2}(\$)\end{array}$ & $\%$ cured & $\begin{array}{c}\text { Median } \\
\text { Duration } \\
\text { (days) }\end{array}$ & $\begin{array}{c}\text { Incremental } \\
\text { Profit per } \\
\text { Customer }^{2}(\$)\end{array}$ \\
\hline Benchmark strategy $^{1}$ & $50 \%$ & 1079 & 647.40 & $50 \%$ & 1103 & 661.80 & $50 \%$ & 1685 & 1011.00 \\
\hline \multicolumn{10}{|l|}{ Recovery probability } \\
\hline \multicolumn{10}{|l|}{ FLT Tenure } \\
\hline Low $25 \%$ & $5 \%$ & 1022 & -34.20 & $0.2 \%$ & 1038 & -39.00 & $12 \%$ & 1070 & -369.00 \\
\hline Top $25 \%$ & $95 \%$ & 1146 & 40.20 & $99.8 \%$ & 1196 & 55.80 & $88 \%$ & $\mathrm{~N} / \mathrm{A}$ & N/A \\
\hline \multicolumn{10}{|l|}{ FLT Revenue } \\
\hline Low $25 \%$ & $43 \%$ & 1069 & -6.00 & $29 \%$ & 1071 & -19.20 & $48 \%$ & 1255 & -258.00 \\
\hline Top $25 \%$ & $57 \%$ & 1090 & 6.60 & $71 \%$ & 1141 & 22.80 & $52 \%$ & N/A & N/A \\
\hline \multicolumn{10}{|l|}{ Win-back } \\
\hline Price & $49 \%$ & 1077 & -1.20 & $50 \%$ & 1103 & 0.00 & $45 \%$ & 1221 & -278.40 \\
\hline Service & $47 \%$ & 1075 & -2.40 & $50 \%$ & 1103 & 0.00 & $37 \%$ & 1154 & -318.60 \\
\hline Price \& service & $54 \%$ & 1085 & 3.60 & $50 \%$ & 1103 & 0.00 & $68 \%$ & N/A & N/A \\
\hline \multicolumn{10}{|l|}{ SLT Marketing } \\
\hline \multicolumn{10}{|l|}{ SLT Recoveries } \\
\hline Remove 1/year & & 1079 & 0.00 & & 1102 & -0.60 & & 1347 & -202.80 \\
\hline Add 1/year & & 1080 & 0.60 & & 1104 & 0.60 & & N/A & N/A \\
\hline \multicolumn{10}{|l|}{ SLT Phone calls } \\
\hline Remove 1/year & & 1059 & -12.00 & & 1080 & -13.80 & & 1208 & -286.20 \\
\hline Add 1/year & & 1101 & 13.20 & & 1128 & 15.00 & & N/A & N/A \\
\hline \multicolumn{10}{|l|}{ SLT Emails } \\
\hline Remove $1 /$ year & & 1063 & -9.60 & & 1084 & -11.40 & & 1221 & -278.40 \\
\hline Add 1/year & & 1097 & 10.80 & & 1123 & 12.00 & & N/A & N/A \\
\hline \multicolumn{10}{|l|}{ SLT Direct mails } \\
\hline Remove $1 /$ year & & 1054 & -15.00 & & 1075 & -16.80 & & 1196 & -293.40 \\
\hline Add 1/year & & 1105 & 15.60 & & 1133 & 18.00 & & N/A & N/A \\
\hline
\end{tabular}

${ }^{1}$ Strategy based on median values of all covariates.

${ }^{2}$ All incremental profits are relative to profits obtained from the benchmark strategy.

${ }^{3}$ The median duration is not specified for cure probabilities higher than $50 \%$ because the point .5 does not belong to the codomain of this survival function. 
FIGURE 1: CUSTOMER RELATIONSHIP TIMELINE

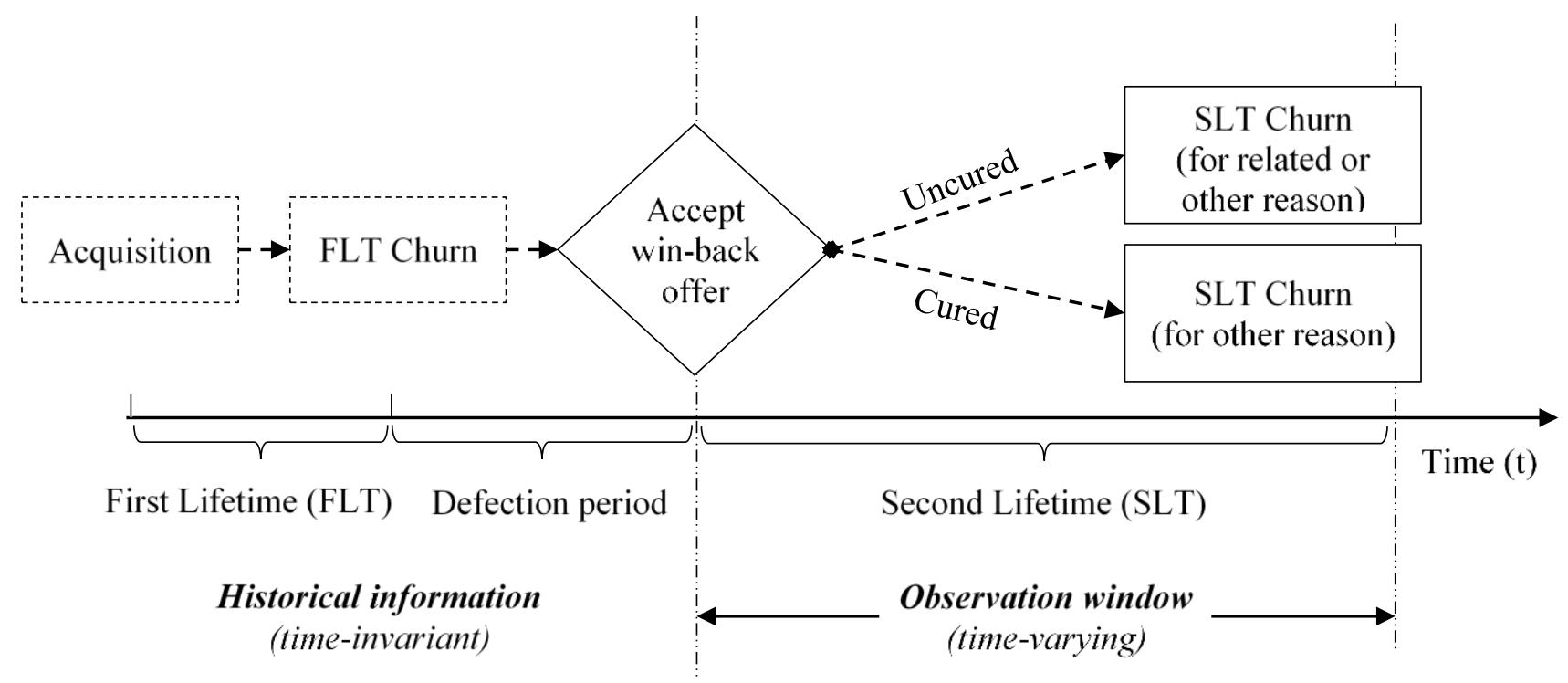


FIGURE 2: CONCEPTUALIZING THE MODELING FRAMEWORK

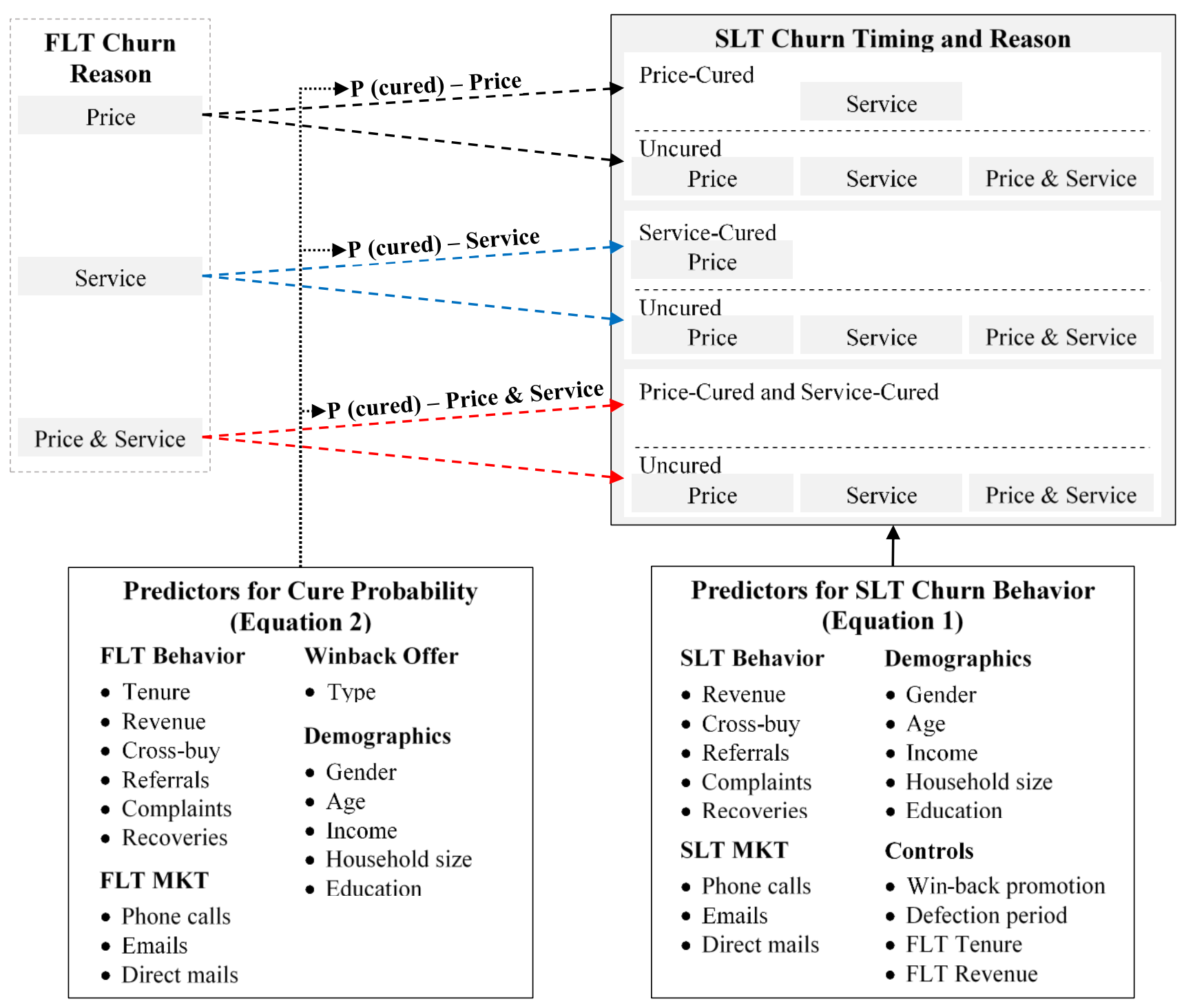




\section{FIGURE 3: CAUSE-SPECIFIC SURVIVAL PROBABILITY ACROSS FLT CHURN REASONS (A-C)}

A. FLT Churn Reason: Price

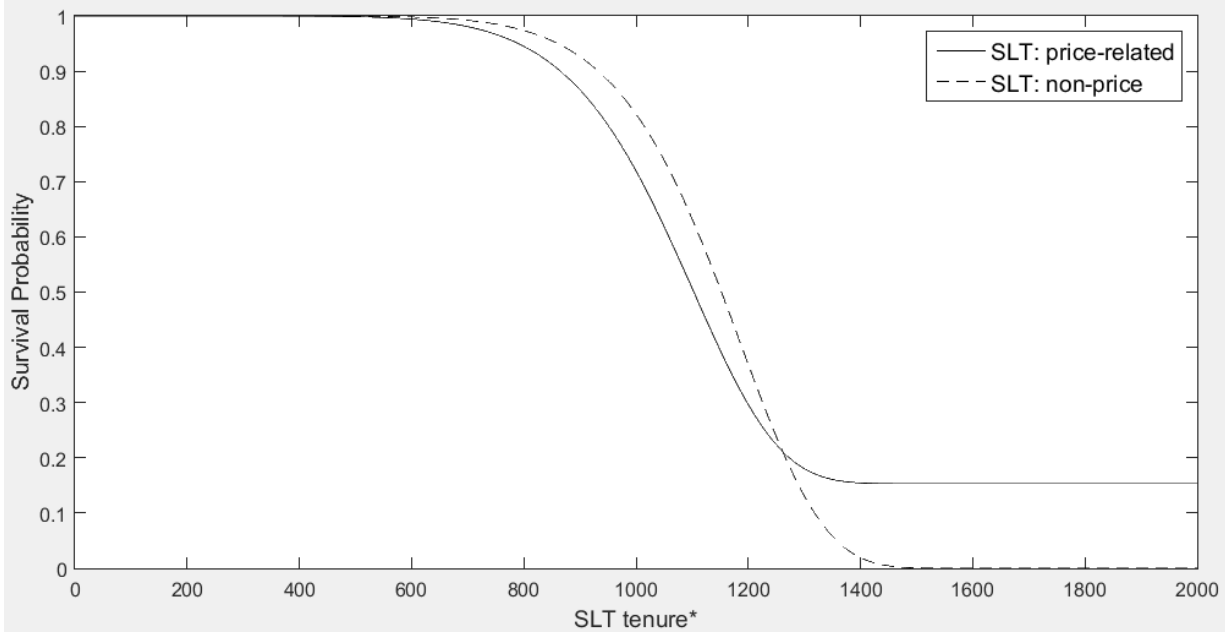

B. FLT Churn Reason: Service

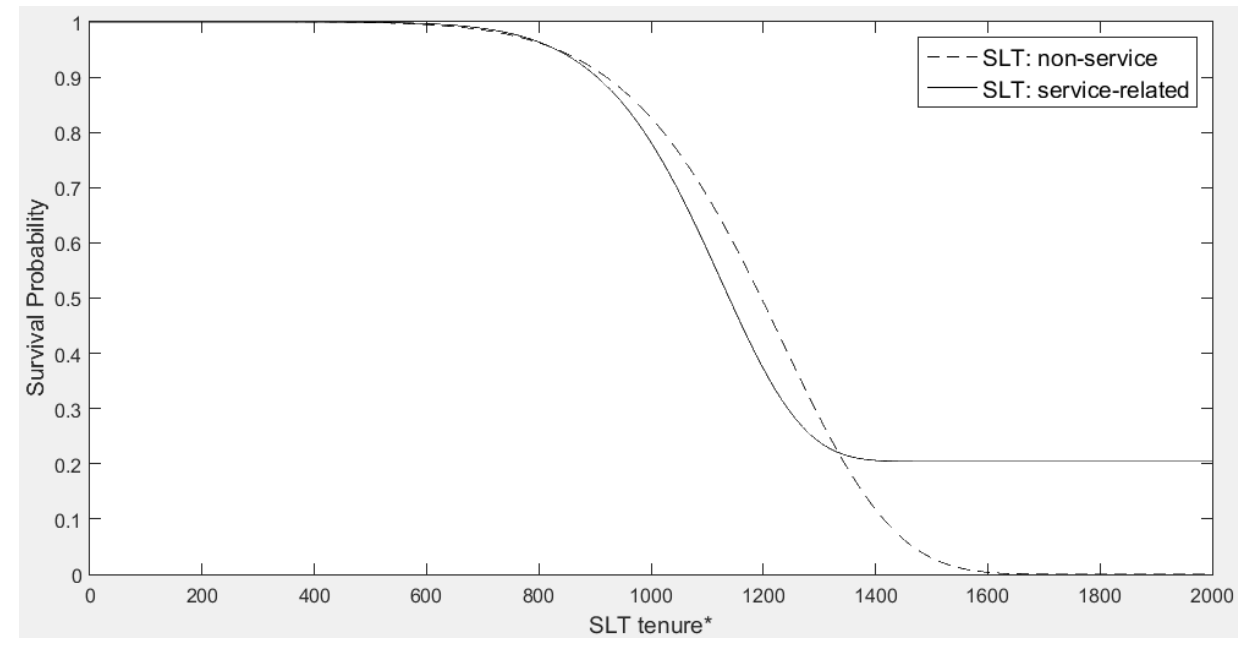

C. FLT Churn Reason: Price and Service

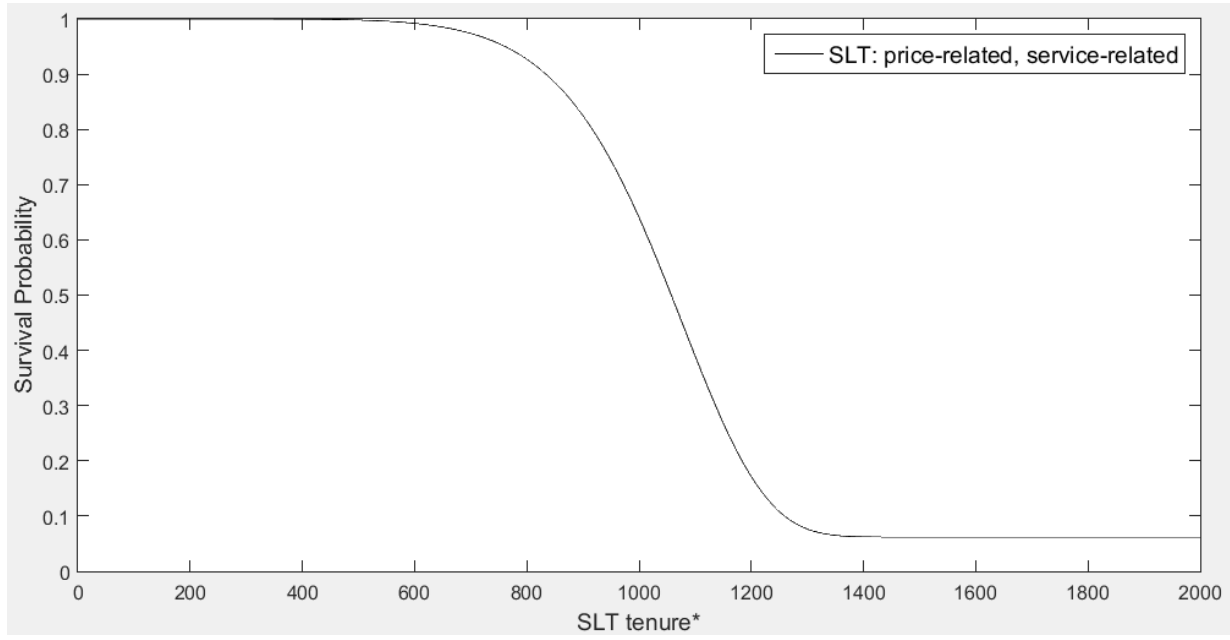

* All tenures are measured in days. 